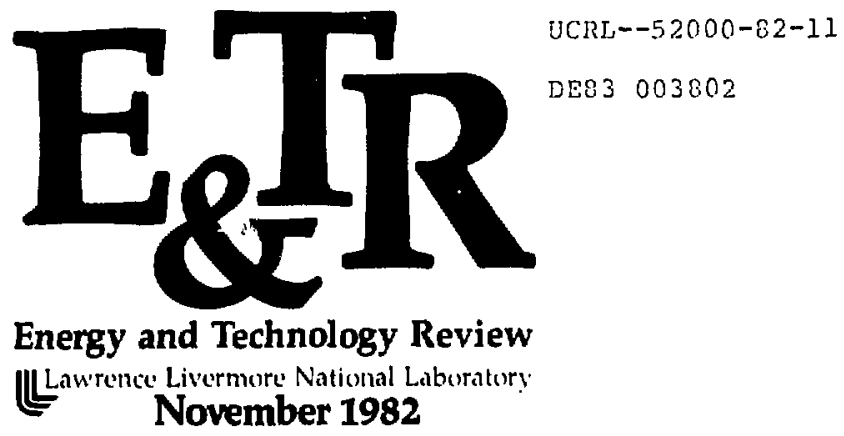

Large-Block Experiments in Underground Coal Gasification Our large-block experiments answered many outstanding questions about underground coal gasification.

The Regional Seismic Test Network

We are studying the performance of a prototype regional : ismic-detection network designed to monitor compliance with the propose- Threshold and Comprehensive Test Ban Treaties.

Understanding Tandem Mirror Devices

Theoretical studies of plasma physics have made crucial contributions to the design of tandem mirror devices now in operation (TMX-Upgrade) and under construction (MFTF-B).

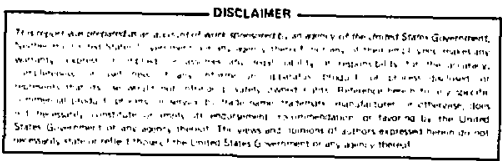




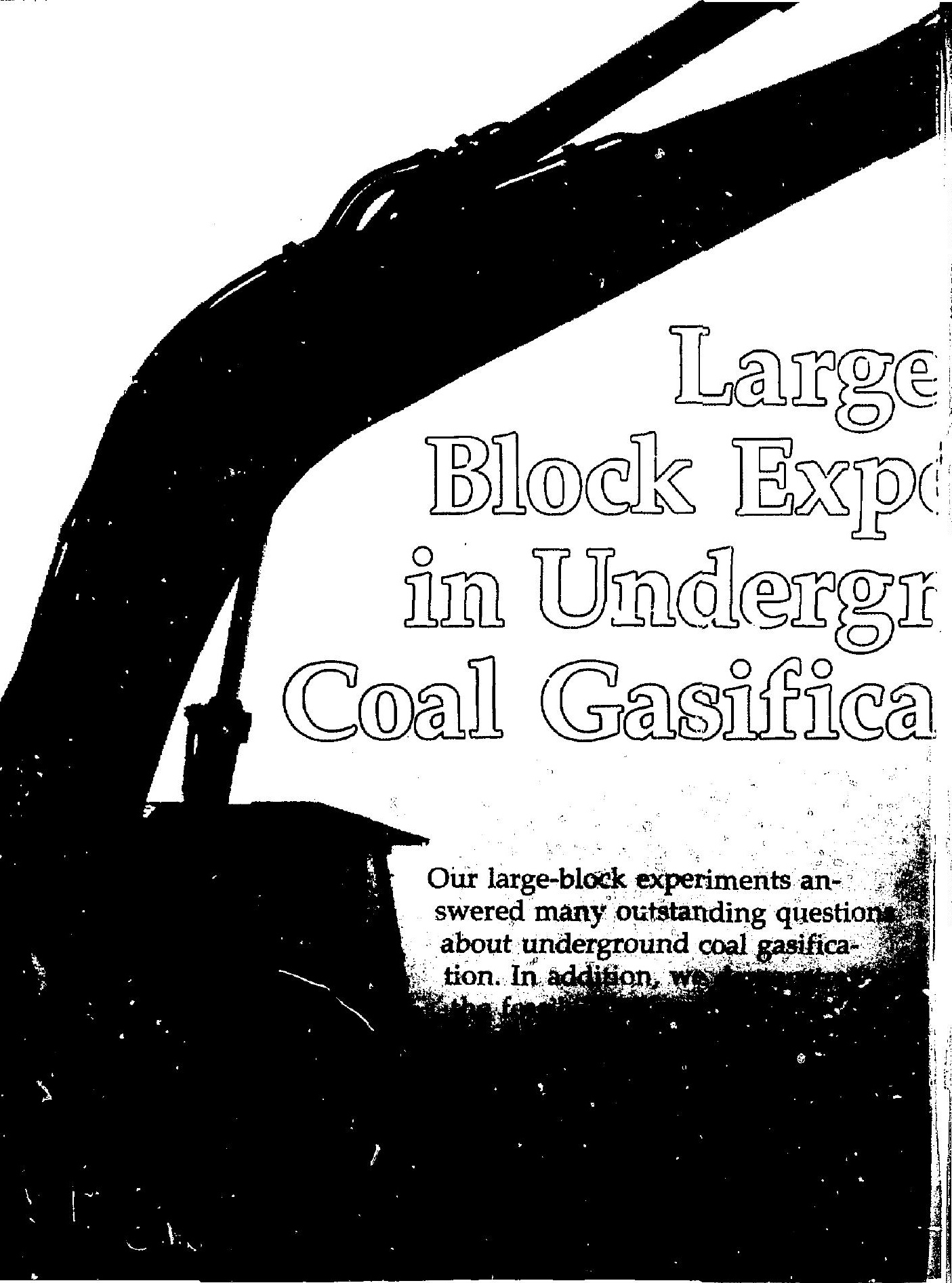


A major objective of the nation's energy program is to develop processes for cleanly producing fuels from coal. One of the more promising of these is underground coal gasification (UCG). If successful, UCG would quadruple recoverable U.S. coal reserves. Projected costs of fuels produced by UCG are 65 to $75 \%$ of those produced by conventional surface-coal conversion pro cesses. In addition, UCG should be more environmentally acceptable than conventional processes, as it requires no mining and produces little solid waste at the surface.

Under the sponsorship of the Department of Energy (DOE), LLNL carried out an early series of UCG field experiments from 1976 through 1979. Called the Hoe Creek series, the tests were designed to develop the basic technology of UCG at low cost. ${ }^{1}$ The experiments were conducted in a $7,6-\mathrm{m}$ thick subbituminous coal seam at a relatively shallow depth of $48 \mathrm{~m}$ at a site near Gillette, Wyoming. On the basis of the Hoe Creek resuits, we planned a more extensive series of field experiments designed to establish the feasibility of UCG for commercial gas production under a variety of gasification conditions. ${ }^{2}$ This series, know $n$ as the large-block experiments, was completed in January 1982. Jointly funded by the DOE and the Gas Research Institute, the large-block experiments were carried out at the Washington Irrigation and Development Company (WIDCO) coal mine near Centralia, Washington, with the cooperation of WIDCO. Originally conceived as a set of tests in large, isolated blocks of coal (hence the term large block), the experiments actually were conducted in adjacent sections of a single exposed coal face.

Conceptually, the process of in situ coal gasification is extremely simple. Two wells are drilled into a coal seam some distance apart and connected by a flow channel through the coal. The coal at the bottom of one of the wells is ignited, and air or a mixture of oxygen and steam is pumped down an injection pipe from the surface to support combustion. The gases produced by the burning coal escape through the flow channel and are removed through the second well. In a commercial-scale system, many such well pairs would be gasified simultaneously. (See the box on p. 2 for a discussion of the chemistry involved in coal gasification.)

In practice, the gasification process is complicated by the fact that as a burn proceeds, the geometry of its reaction volume constantly changes. In its early stages, the cavity created by a burn is empty and lies entirely within the coal seam. As the coal continues to burn, the roof of the cavity collapses and

\section{Fundamentals of Coal Gasification}

All coal gasification processes, including underground coal : siffcation, involve the following basic chemical reaction:

$$
\text { Coal }+ \text { Heat } \rightarrow \text { Char }+ \text { Tar }+ \text { Water }+ \text { Gases . }
$$

This pyrolysis reaction proceeds rapidly, requiring relatively modest amounts of heat. The gases produced include hydrogen, carbon monoxide, and methane (desired species) and carbon dioxide and hydrogen sulfide (undesired species). Solid particles often are entrained in the product gases and brought to the surface where they must be filtered out.

Char, the principal carbonaceous product of coal pyrolysis, is a hydrocarbon with a hydrogen-carbon atomic ratio of 0.1 to 0.4 , depending on the temperature $t$ which the pyrolysis takes place. The char is formed by the heat generated from the burning of the coal with injected oxygen. In the more detailed reactions shown below, we have substituted carbon (specifically $\beta$-graphite) for the char to show simple stoichiometry and exact heats of reaction, even though char (not carbon) is the actual reactant.

There are two oxidation reactions involved, both of which are fast and liberate considerable energy:

$$
\begin{aligned}
& \mathrm{C}+\mathrm{O}_{2} \rightarrow \mathrm{CO}_{2}+393.5 \mathrm{~kJ} / \mathrm{mol}, \\
& \mathrm{C}+1 / 2 \mathrm{O}_{2} \rightarrow \mathrm{CO}+110.5 \mathrm{~kJ} / \mathrm{mol} .
\end{aligned}
$$

The gasification reactions ahsorb considerable energy and are slower than oxidation. The reverse of the second gasification reaction is undesirable and fortunately quite slow:

$$
\begin{aligned}
& \mathrm{C}+\mathrm{H}_{2} \mathrm{O} \rightarrow \mathrm{CO}+\mathrm{H}_{2}-131.4 \mathrm{~kJ} / \mathrm{mol}, \\
& \mathrm{C}+\mathrm{CO}_{2} \rightleftharpoons 2 \mathrm{CO}-172.4 \mathrm{~kJ} / \mathrm{mol} .
\end{aligned}
$$


partly fills it with rubble, changing the flow patterns and the subsequent burn geometry.

One goal of our large-block experiments was to provide a better understanding of how the burn cavity grows and is influenced by the geology of the site. In a large-scale burn, the combustion heat lost to inert roof material eventually causes the heating value of the effluent gases to decline to an uneconomic level. At this point, the burn normally must be terminated.

Another goal of our large-block experiments was to explore the feasibility of extending gas production from a well using the controlled retracting injection point (CRIP) method. ${ }^{3}$ The basic idea of the CRIP technique is to start a new burn zone in fresh coal by cutting off the injection pipe at a point upstream of the old cavity and then re-igniting the coal seam.

The process of $m$ situ coal gasification is difficult, if not impossible, to observe directly in detail. Run to completion, full-scale field tests destroy all evidence of the early stages of burncavity growth. Laboratery studies of burn cavity growth in small coal blocks ${ }^{\dagger}$ are too small to study more than the very early stages of growth. Until now, these constraints have limited our understanding of how the growth of the burn cavity is affected by process variables (such as the ratio of injected oxygen to steam) and, in turn, affects gas composition and resource recovery.

\section{Design of the Experiments}

The site of our large-block experiments was the Big Dirty seam, an exposed coal face in the Bucoda field of the WIDCO mine. ${ }^{5}$ The Big Dirty is part of the Late Eocene Skookunchuck formation, which has a consideralile extent in the Centralia-Chehalis district of Washington. It is estinuated that the Big Dirty seam alone contains 305 million tonnes of coal reserves with a seam thickness greater than $3 \mathrm{~m}$ and ranging in depth from 90 to $300 \mathrm{~m}$. WIDCO has mined the seam by surface methods for about nine years at an annual production rate of about 5 million tonnes to fuel the adjacent 1200-MWe Centralia Steam Electric Plant. Because of its low permeability, there are no important aquifers in this formation; however, permeability has been somewhat increased by fracturing of the coal outcrop and extensive earth work at the site. The coal itself is subbituminous and contains considerable ash in the form of stringers. The average composition of the coal is $35 \%$ fixed carbon, $22 \%$ moisture, $14 \%$ ash, and $29 \%$ volatiles.
The water-gas-shift reaction is quite rapid and in gasification models is often assumed to be at equilibrium:

$$
\mathrm{CO}+\mathrm{H}_{2} \mathrm{O} \rightleftharpoons \mathrm{CO}_{2}+\mathrm{H}_{2}+41.00 \mathrm{~kJ} / \mathrm{mol} \text {. }
$$

Char methanation is a highly desirable reaction but unfortunately is very slow:

$$
\mathrm{C}+2 \mathrm{H}_{2} \rightarrow \mathrm{CH}_{4}+74.89 \mathrm{~kJ} / \mathrm{mol} \text {. }
$$

In coal gasification, added oxygen (injected either as air or as steam and oxygen) is required to provide the heat necessary to drive the oxidation and gasification reactions. These reactions are limited both by kinetics (i.e., reaction rates) and thermodynamics (i.e., equilibrium considerations). At higher temperatures, the production of hydrogen and carbon monoxide is favored; at lower temperatures, carbon dioxide and methane production is favored. In addition, high pressures favor the formation of meth- ane. Unfortunately, methanation reactions are slow in underground coal gasification.

The gases produced from coal gasification also contain undesirable species such as carbon dioxide and hydrogen sulfide. These gases, plus any solid particles entrained in the gas and brought to the surface, must be removed in surface processing facilities. The "cleaned" gas, now containing hydrogen, carbon monoxide, and methane, can be transported by pipeline several hundred miles for use elsewhere. The gas also can be converted at the production site into other products such as methanol, gasoline, synthetic natural gas, electricity, or chemicals such as ammonia. These products can then be economically transported for great distances, permitting even a remotely located coal deposit to be utilized commercially. When air is injected instead of steam and oxygen, the product gas is diluted with inert nitrogen and cannot be economically transported more than a few miles. Such a gas is a local fuel suitable for electrical power generation or industrial heat. 
To prepare the experiments, we drilled horizontal injection wells about $13 \mathrm{~cm}$ in diameter and about $30 \mathrm{~m}$ long into the face of the coal seam parallel to its floor (Fig. 1). A stainless-steel liner was inserted in each injection well to carry the steam-oxygen combustion mixture. The production wells were drilled vertically from the surface above the seam to intersect the injection wells. The production wells were positioned far enough beyond the maximum expected cavity limit to ensure survival of their casings and to limit gas leaks to the surface. Five well pairs were constructed for the burn experiments (Fib, 2). (A sixth pair was used as a dewatering well.)

To permit real-time observation of the burn cavities, we drilled an additional well $15 \mathrm{~cm}$ in diameter and outfitted with a fused quartz window over the estimated highest point of each cavity. In addition, we installed a small number of thermocouples in special wells for each test (see Fig. 1). Most of the information on the burn cavities, however, was obtained from post-burn excavation. To enable us to study cavity shape early in a burn, the total burn time in each experiment was thus relatively brief (about 4 days).

The last experiment was a test of the CRIP technique (location 1 in Fig. 2). The injection well was drilled $1.8 \mathrm{~m}$ below the roof of the coal seam to ensure that the burn zone would intersect the roof. To allow for a $7-\mathrm{m}$ retraction of the injection point, the injection liner was extended $7 \mathrm{~m}$ farther into the drilled hole than the other experiments The thermocouple wells were arranged to measure both CRIP cavities.

\section{Process Instrumentation}

In addition to the cavity-temperature data provided by the in situ thermocouples, effluent gases produced in each experiment were continuously monitored and analyzed. The instrumentation was

Fig. 1

General elevation yow of the eecond, third, fourth, and fifth lerge-block UCG experiments. The oxygen lance was a steinlese-ateel plpe inserted into the injection channel, which was drilted about $7.6 \mathrm{~m}$ below the roof of the coes seam. The average depth of the production well to its interesction with. the injection channol wes about $24 \mathrm{~m}$.

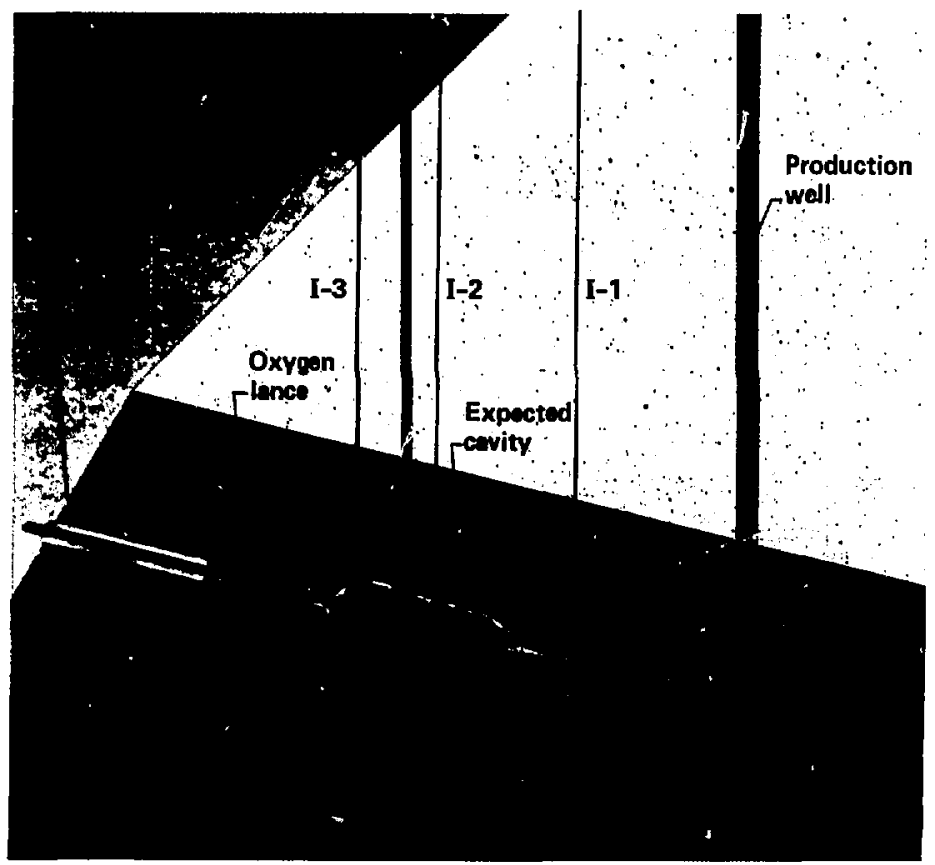




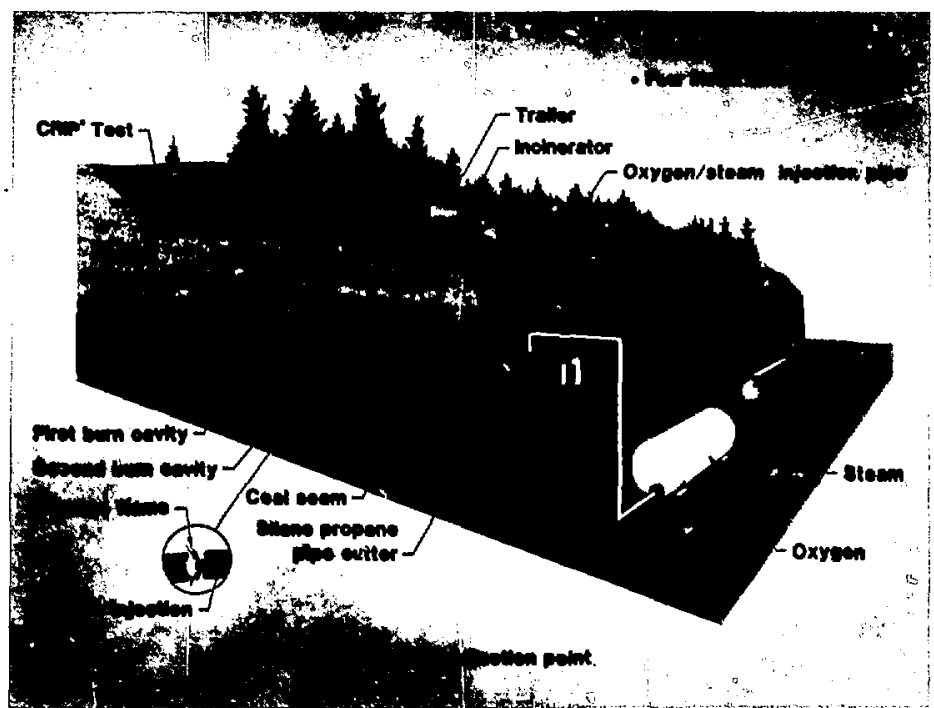

virtually identical to that used in the earlier Hoe Creek field experiments and in the laboratory experiments in Livermore. A data logger, a data-aquisition computer, and the gas-analysis instrumentation were housed in a trailer at the test site. The data logger received all the signals from transducers on the flow-orifice stations and from the in situ thermocouples and transmitted them to the computer. The real-time results of the computer analysis were displayed on television monitors and recorded on hard copy.

Because of the short duration of each experiment, we used an almost-triply redundant gas analysis system to minimize any data lost from instrumentation down time. A clean product-gas sample from the production well was fed to a gas chromatograph, a time-offlight mass spectrometer, and continuous analyzers that measured oxygen, carbon monoxide, and carbon dioxide content. Gas flow was controlled by electrical valves. In addition, a hot gas sample was analyzed for water content in a dedicated gas chromatograph. Water content was also measured by chilling the gas in the gas and condensing the water in the clean-up system.

\section{Coal Ignition System}

In the Hce Creek experiments, we used electrical resistance heaters to ig nite a charge of charcoal that in turn ignited the coal. Such a procedure is poorly adapted to horizontal wells, however, especially in larger field tests and for commercial UCG systems, where the coal may be quite deep and pipes correrpondingly longer.

To provide a simple and rugged system that could be reignited as often as desired, we used propane gas ignited by silane $\left(\mathrm{SiH}_{4}\right)$, a pyrophoric gas (one that ignites in the presence of oxygen). After establishing an enriched oxygen flow in the injection well, we introduced a silane slug that ignited. We then valved on the propane, which serves as the sustaining fuel, and slowly increased its flow. In a pure oxygen environment, propane can generate temperatures near $2000^{\circ} \mathrm{C}$. Such temperatures are adequate both to ignite the coal seam and to melt through the metal pipe when required (as in the CRIP experiment). The propare flow, which was maintained for as little as $7 \mathrm{~min}$, was completely successful in igniting the coal; even shorter periods probably would suffice.
Fig. 2

vlew of the large-block teat site showing the locatlon and exporimental eotup the CRIP tout. 


\section{Conducting the Experiments}

The five UCG tests took place over a period of about seven weeks from November 1981 through January 1982. Table 1 shows the test chronology and process variables. The time counter in the data-aquisition system was reset to zero at 0:00 hours of the starting date for each test, and run time was accumulated in decimal days. To enable us to directly compare final cavity shapes, we injected the same total amount of oxygen during each experiment and terminated the burn when $25 \mathrm{~m}^{3}$ of coal were consumed.

\section{In all five tests, there was a rapid increase in flow resistance and a corresponding increase in injection
pressure that caused considerable gas
leakage out of the open coal face... corresponding increase in injection
pressure that caused considerable gas
leakage out of the open coal face... corresponding increase in injection
pressure that caused considerable gas
leakage out of the open coal face...}

Combustion gases were injected on two basic flow-rate schedules, fast and slow. The slow scheduie typically gave a maximum flow rate of $3 \mathrm{~mol} / \mathrm{s}$ over a period of 120 hours and the fast schedule a maximum flow rate of $6 \mathrm{~mol} / \mathrm{s}$ over $\mathbf{5 0}$ hours. The schedules were chosen to produce, if continued, an oxygen flow rate of $15 \mathrm{~mol} / \mathrm{s}$ in 4.5 days on a fast schedule and 12.5 days on a slow schedule. In each schedule, we increased the flow rate $f$ from low to peak levels according to $f=k t^{2}$, where $k$ is a constant and $t$ is the elapsed time. By making the flow rate proportional to $t^{2}$, we maintained a constant relation between the surface area of the cavity and the oxygen flow rate.

The first of the five large-block tests, LBK-5, was conducted in three segments. The first 1.5 days were devoted to training the operating crew; the next day to trying short periods of various steam-oxygen injection ratios, and the final day to air injection.

In all five tests, there was a rapid increase in flow resistance and a corresponding increase in injection pressure that caused considerable gas leakage out of the open coal face and a arop in the pressure of the product gas. The results of the post-burn excavation indicate that the blockage resulted from a large bed of coal, char, and ash rubble that formed in the burn cavity and extended down the drilled channel.

During the tests, various operational changes were made to try to alleviate the product-gas pressure drop. In the second experiment, LBK-2, the oxygen flow was increased suddenly to try to open the channel but the attempt failed when slag formed and plugged the injection channel. Reverse combustion (i.e., igniting a burn at the production well and propagating it back against

Table 1 Chronology and major prosess variables of the large-block :oal gasification tests. The numerical designation of each test corresponds to the locations shuwn in Fig. 2.

\begin{tabular}{|llllll|}
\hline & $\begin{array}{l}\text { Date } \\
\text { (1981-1982) }\end{array}$ & $\begin{array}{l}\text { Ignition time, } \\
\text { decimal days }\end{array}$ & $\begin{array}{l}\text { End time, } \\
\text { decimal days }\end{array}$ & $\begin{array}{l}\text { Flow } \\
\text { schedule }\end{array}$ & $\begin{array}{l}\text { Steam-oxygen } \\
\text { ratio }\end{array}$ \\
\hline LBK-5 & Nov. 21-Nov. 24 & $\mathbf{0 . 6 4}$ & 3.85 & fast & s:1, 2:1, 3:1" \\
LBK-2 & Dec. 3-Dec. 7 & $\mathbf{0 . 6 3}$ & 4.30 & slow & $1: 1$ \\
LBK-3 & Dec. 10-Dec. 16 & $\mathbf{0 . 4 4}$ & 6.29 & slow & $3: 1$ \\
LBK-4 & Jan. 7-Jan. 10 & $\mathbf{0 . 6 7}$ & 3.96 & fast & $1: 1$ \\
LBK-1 & Jan. 12-Jan. 16 & $\mathbf{0 . 6 3}$ & 4.51 & fast & $3: 1$ \\
\hline
\end{tabular}




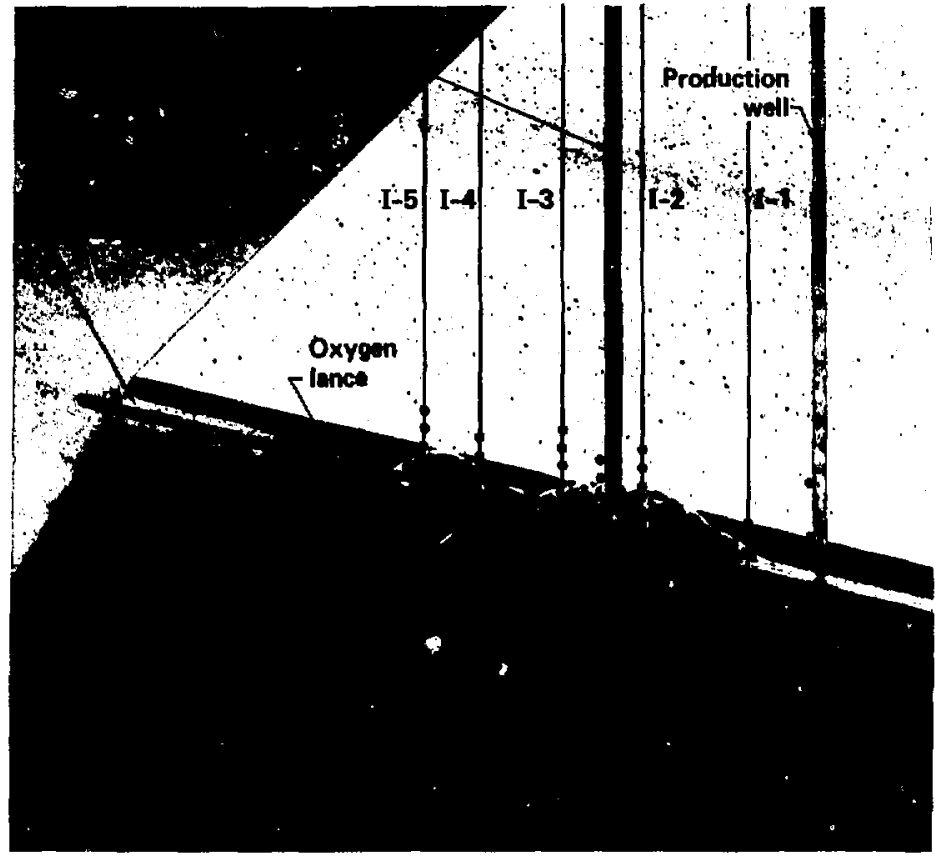

the flow to the injection well) was used in LBK-3 and LBK-4 with no real improvement (i.e., reduction) in total gas loss. For LBK-1, the channel was reamed out to $20 \mathrm{~cm}$ in diameter before the burn was started. This did improve the flow characteristics and reduce the pressure drop. However, after a short period of reculuced flow (due to a delayed delivery of oxygen), the flow resistance rose. It was not possibl $\_$to return to the original high flow rate, although the gas loss was not as great as for the previous four tests.

\section{CRIP Experiment}

The CRIP experiment was conducted in the same well pair as the fifth test, LBK-1 (Fig. 3). To sever the injection liner, we set the ignitor at a position $7.3 \mathrm{~m}$ back from its end, opposite the renter of a set of three thermocouples $1.5 \mathrm{~m}$ upstream of I-5 (see Fig. 3). After cutting back on the injection flow, we re-ignited the ignitor and then, shifting to pure oxygen with a propane flame, burned off the injection liner and ignited the coal at the new location.

We then returned to forward burn with a 3:1 steam-oxygen ratio on a somewhat accelerated flow-rate schedule. After a little more than a half day of operation, the temperature at the $0.6-\mathrm{m}$ level of $1-5$ rose to $905^{\circ} \mathrm{C}$, confirming a burn cavity at the new location. After a full day of operating at the new injection point, we shut off the flow and ended the experiment.

\section{Analysis of the Experiments}

\section{Flow-Rate Effects}

We examined two possible kinds of flow-rate effects: those associated with the use of different schedules in different experiments and those associated with flow-rate changes during a single

\section{Fig. 3}

View of the CaIP experiment. To enhance interactlon of the burn cavily whit the roof of the coal.seam (dip angle 15 deg), the injection channel was drilled only $1.8 \mathrm{~m}$ below the root. Addr. tional thermocouple wells were installed to detect the presence of the ancond burn cavity. 
periment. Table 2 summarizes gas quality for the five experiments. Discounting other factors (such as steam-oxygen ratio, location, and percent of gas recovery), the slow schedule seems to have delivered gas with a slightly higher heating value. The experiments producing the two highest heating values, however, also showed the two highest levels of gas loss, possibly introducing sampling errors. Although the slow-schedule experiments seem to have produced higher carbon monoxide and lower carbon dioxide levels, omitting the truncated LBK-2 experiment causes the differences to disappear. We concluded that the different flow-rate schedules had no significant effect on gas quality. Flow-rate schedules likewise had no discemible effect on the other important process result, namely the flow resistance of the product gas.

The second type of flow-rate effect was produced by varving flow rates during an experiment. Flow-rate changes had the largest exfect on gas composition during the early low-flow period; in general, correlations between flow rates and changes in gas composition disappeared at higher flow rates.

\section{Steam-Oxygen Effects}

One of the few controlliole operating parameters in in situ coal gasification is the composition of the injected steam-oxygen gas. We therefore designed the large-block tests with this in mind. Table 2 shows the ratios used in each experiment. The bulk of our data came from the LBK-5 test, in which we used a series of ratios, each starting and ending at 1:1. Each ratio was maintained for about 4 hours. During this time, we also changed the oxygen injection rate in a stepwise fashion in accordance with a fast $\left(t^{2}\right)$ flow schedule. Each oxygen flow plateau was also maintained for 4 hours, but was staggered by 2 hours from changes in the the steam-nxygen ratio.

As shown in Fig. 4, changing the steam-oxygen ratio had a small effect on the composition of the dry product gas. The changes were most pronounced for carbon monoxide, carbon dioxide, and hydrogen. Although methane concentration may also have been affected, large periodic variations in its value make changes difficult to see. Changes in ethene or ethane concentratiun do not appear to correlate at all with the steam-oxygen ratio. It appears that the effect of changes in the steamoxygen ratio are more pronounced at lower oxygen flow rates, as is the effect of flow rate itself.

Although the observed direction of change in concentrations of carbon monoxide, carbon dioxide, and hydrogen was consistent with laboratory and modeling results, their magnitude was considerably smaller in the full-size field tests. This difference may have resulted from alterations, in the larger tests, in the size of the active gasification zone. Lowering the steam-oxygen

Table 2 summary of experimental results for the large-block coal gasification tests.

\begin{tabular}{|c|c|c|c|c|c|c|c|c|c|c|}
\hline \multirow[b]{2}{*}{ Experiment } & \multirow[b]{2}{*}{$\begin{array}{l}\text { Flow } \\
\text { schedule }\end{array}$} & \multirow[b]{2}{*}{$\begin{array}{l}\text { Steam-oxygen } \\
\text { ratio }\end{array}$} & \multirow[b]{2}{*}{$\begin{array}{l}\text { Product gas } \\
\text { recovery, \% }\end{array}$} & \multirow{2}{*}{$\begin{array}{l}\text { Yeat of } \\
\text { combustion, } \\
\text { kJ/mol }\end{array}$} & \multicolumn{6}{|c|}{ Composition of dry product gas, vol\% } \\
\hline & & & & & Hydroge" & $\begin{array}{l}\text { Carbon } \\
\text { monoxide }\end{array}$ & $\begin{array}{l}\text { Carbon } \\
\text { dioxide }\end{array}$ & Methane & Ethene & Ethane \\
\hline LBK-5 & fast & $1: 1,2: 1,3: 1^{\star}$ & $\Leftrightarrow$ & 241 & 46 & 20 & 28 & 4.8 & 0.16 & 0.34 \\
\hline LBK-2 & slow & $1: 1$ & 45 & 251 & 38 & 33 & 22 & 4.0 & 0.32 & 0.25 \\
\hline LBK-3 & slow & $3: 1$ & 21 & 251 & 45 & 23 & 27 & 5.3 & 0.24 & 0.39 \\
\hline LBK-4 & fast & $1: 1$ & 52 & 242 & 43 & 20 & 28 & 5.0 & 0.20 & 0.37 \\
\hline LBK-1 ${ }^{b}$ & fast & $3: 1$ & 85 & 231 & 42 & 25 & 28 & 3.5 & 0.34 & 0.11 \\
\hline
\end{tabular}




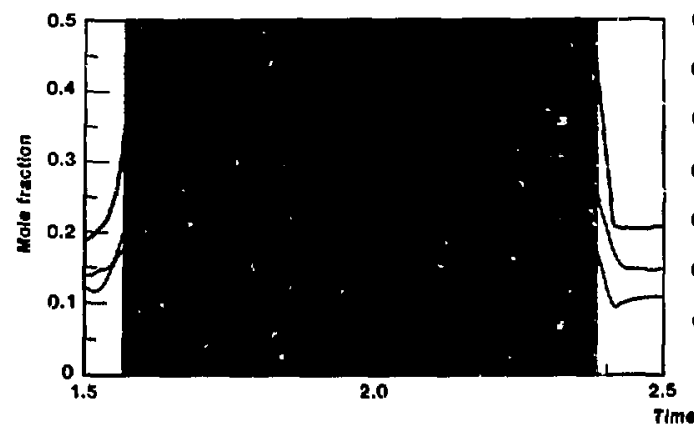

Time, daye

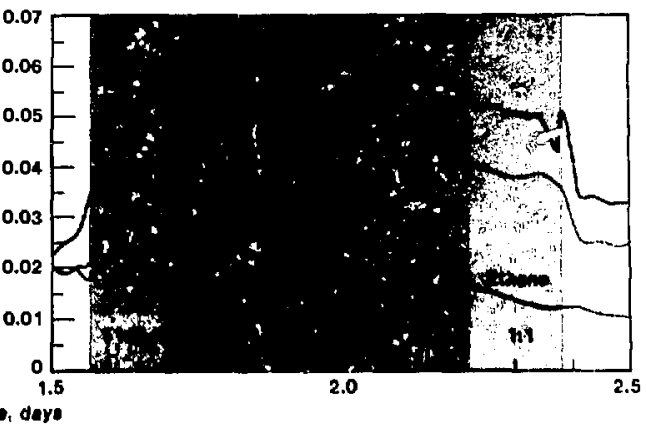

ratio can cause the regions near the injection point to become water starved (that is, there is not enough water available for the char-steam reaction to absorb the energy released by the combustion of the oxygen). When that happens, the active gasification zone must expand. As a result, more of the water generated from coal drying, coal pyrolysis, and in-situ influx is able to enter the active zone to be consumed. When the steam-oxygen ratio is increased, the opposite occurs. The underground system is thus self-stabilizing with respect to changes in the steam-oxygen ratio, whose effect on the composition of the product gas is consequently less than predicted on the basis of laboratory and modeling studies.

In contrast to the short-term response data on variations in dry-gas composition with steam-oxygen ratio, the average data for the five experiments showed no clear pattern (see Table 2). In fact, with the exception of LBK-2, the results show little difference. This tends to strengthen the evidence for a self-stabilizing active gasification zone that, within limits, yields the same results regardless of the composition of the injected gas.

\section{Modeling Product-Gas Composition}

In our previous studies, we used a relatively simple model to predict the composition of the product gas. The same model was applied to the large- wock tests. The nodel divides the underground processes into several simple process zones-reaction, pyrolysis and drying, and mixing-coupled by material and energy transport. (Pyrolysis is the process by which complex molecules are broken down by heat into simpler units.) We assume that the gas leaving the reaction zone is in watergas-shift equilibrium at a characteristic reaction temperature $t_{R}$. This temperature can be thought of as the lower limit below which the primary gasification reaction of water plus char becomes negligible. Calculations have shown that results are not strongly influenced by the water-gas-shift temperature chosen.

The model distributes excess heat (above what is required to make the reaction products) between that transferred to the pyrolysis-drying zone and that lost to the surrounclings. In the pyrolysis-drying zone, energy supplied directly or indirectly from the reaction zone comes in cuntact with native coal, producing pyrolysis gases, cha:; and ash. The pyrolysis gases (including tar) are then split, with a portion passing through the reaction zone and the rest mixing downstream. The ash and a portion of the produced char enter the reaction zone, and the remaining char is unused. The energy required to produce a given amount of char depends on the type of coal, including its water and ash content, and the amount of erergy lost from the pyrolysis-drying zone to the surroundings.
Fig. 4

Composition of the dry product gas dufing the sieam-oxygen Injectlon phase of the L.EK.5 experiment. 
We used this model to match the results of the pre-CRIP LBK-1 experiment. To do so, we found it necessary to use a higher $t_{\mathrm{R}}\left(1000^{\circ} \mathrm{C}\right)$ than in matching the results from the full-size field tests but lower than those used in matching our small-scale laboratory results. As, however, the value of $t_{R}$ is a measure of the temperature at which the char-steam reactions are slow in a given system, it appears consistent with the relative size of the large-block experiments, midway between the laboratory tests and the large-scale field tests. This $t_{\mathrm{R}}$ is alse consistent with data from the thermocouples and optical pyrometry, which recorded temperatures of about $1070^{\circ} \mathrm{C}$.

Our model also indicated that all heat losses from the reaction zone went to pyrolyzing and drying coal, with litthe net heat loss from the system. As most of the L.BK-1 test was performed with the cavity and link entirely within the coal seam, this result seems quite reasonable.

Finally, the modei showed that all in situ water influx to the system occurred downstream of the reaction zone, in the mix zone. The degree of pyrolysis gas recycling to the reaction zone was $60 \%$, indicating that much of the drying and pyrolysis of the coal probably occurred near the oxygen injection point. This result is consistent with the development of a rubble-fillcd cavity in which considerable mixing occurs.

Because of the substantial loss of product gas observed in the other large-block tests, they were not as revealing as those of the LBK-1 experiment. Such losses provide too much latitude in the selection of model parameters, obscuring insights into the process.

\section{Flow Resistance}

Although we cannot predict with certainty the trend of flow resistance for larger, long-term tests, the results of the large-block tests are suggestive. First, if the increase of resistance is a result of rubble accumulativin, and if the rubble contains a reasonable amount of char, the quality of the gas produced before it interacts strongly with the roof (and thus suffers a decline in heating value) should be excellent. Gas quality should also be independent of cavity shape and system flow rates. A small amount of packed rubble creates a very efficient interchange between gas and solid phases, leading to efficient use of energy in the gas to produce hydrogen and carbon monoxide.

Second, a more direct effect of flowresistance increase may be an operational penalty. This can occur in two ways. If the pressure drop is distributed along the entire length of the open hole, the flow resistance for a burn in a relatively long hole should scale directly with its length, causing an excessively high pressure drop. Alternatively. if the pressure drop occurs mainily near the confluence of the product flow into the link, it is independent of the overall length of the system. Unfortunately, our results do not provide clear evidence as to which mode of flowresistance increase predominated.

\section{Resul's of the CRIP Experiment}

After severing the injection liner and re-igniting the coal in the new location, we noted two changes in the system. First, the flow resistance of the product gas initially dropped and then increased to a plateau higher than that during much of the pre-CRIP burn. However, the increase in resistance preceded the CRIP experiment and probably resulted from reduced flow during the oxygen-loss and air-flow periods. The post-CRIP resistance plateau was, in fact, lower than that for tests 2 through 5 , indicating that the pipe left in the hole did not unduly restrict the flow.

The other effect of cutting the injection liner was a change in product-gas composition. Post-CRIP gas contained considerably more methane, ethane, and carbon dioxide than pre-CRIP gas. We attribute this to an increased contribution of pyrolysis products to the final gas, resulting from the large, hot cavity created by the pre-CRIP burn. This effect should begin to disappear as the flow reaches pre-CRIP levels. 
Because of the exaggerated role of pyrolysis products in the post-CRIP gas, its relatively low flow rates, and the absence of heating-value degradation in the pre-CRIP gas, the CRIP test did not demonstrate recovery from conditions of low gas quality. However, we believe that the heating value of the gas would recover in a large-scale system more heavily affected by roof interaction.

\section{Post-Burn Excavations}

Our post-burn excavations were carried out with earth-moving machinery. The cavities all had a basically oval cross section that varied from a vertical-to-horizontal aspect ratio of 2:1 at their ends to nearly $1: 1$ at their center. The largest cross section was always a metre or so downstream from the injection point (excluding the CRIP experiment). The cavities were largely filled with rubble consisting of dried coal, char, and ash.

In no case was there an open channel completely through the cavity. Some sections of the channels were easily identified, and the rubble could be cleaned out by hand. In other section:, we could discern no definite channel. Figure 5 is a cross-sectional photograph of the burn cavity created in the fifth experiment.

Experiments with a steam-oxygen ratio of 1:1 (the second and fourth) showed variations in their cavity cross section that corresponded to the burning off of $10 \mathrm{~m}$ of injection liner in both tests. At this stage of our analysis, there are no other obvious differences in cavity shapes that are related to the composition or flow rate of the injection gas.

The reverse burn of the channel in the fourth experiment affected an oval coal region about $1 \mathrm{~m}$ high by $0.5 \mathrm{~m}$ wide. The affected coal was quite friable and completely filled the area. The original drilled hole was faintly visible as a difference in texture in some of the exposures.

We had enlarged the channel in the fifth experiment by drilling it to $20 \mathrm{~cm}$ in diameter. The initial drop and subsequent increase in flow resistance

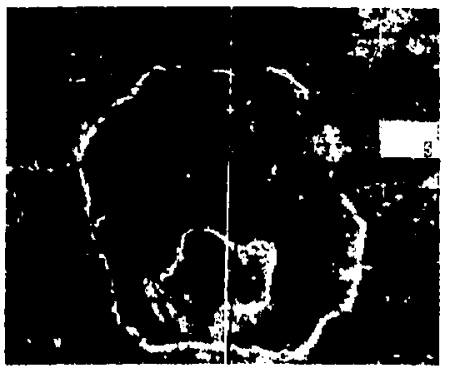

Fig. 5

Photograph of the the fifth crosssectional slice of the burn cavity in the fith experiment, near the end of the injection liner. The white paint shows the boundary of the affecled coal and the red line the boundary of the charred coal. The inner white lino marks the high-ash zone. Rad dots indlcate where samplea were taken for analyeis. Grid lines are $1 \mathrm{~m}$ apart. produced a large amount of particulate material during the burn. On excavating, we found a region about $1 \mathrm{~m}$ in diameter and about $6 \mathrm{~m}$ long almost filled with altered coal and ash. There was a small zone of partly open space 25 to $30 \mathrm{~cm}$ high along the roof and a cylindrical open chamber 1 to $2 \mathrm{~m}$ in diameter around the base of the production well up to the roof. Presumably, the hot product gas had swirled, eroding the coal and producing the void space.

\section{Future Work}

The results of the large-block experiments indicate that the coal in the Big Dirty seam is quite suitable for in sitt gasification and that our technique may provide the additional control needed for successful commercialization. Encouraged by these results, we are proposing a series of tests to be carried out jointly by LLNL and the Washington Water Power Corporation, WIDCO's parent company. Our proof-of-concept experiment, called the partial-seam CRIP test, is designed to operate in half the thickness of the coal seam, will allow for four or five injection-point withdrawals, and will study the composition of the product gas and the efficiency of recovering energy from the coal.

In contrast to the large-block experiments, we plan to drill the production channel above the injection channel and slanting in from the side (Fig. 6). This will provide maximum protection against slag plugging in the Big Dirty's high-ash (14\%) coal. As the burn cavity is moved back upstream by successive 
Fig. 6

Viaw of a planned CAIP experiment in which the production channel is drilled above the injection channel and slanted in from the side. Thla should prevent alag from plegging the pro. duction channal.

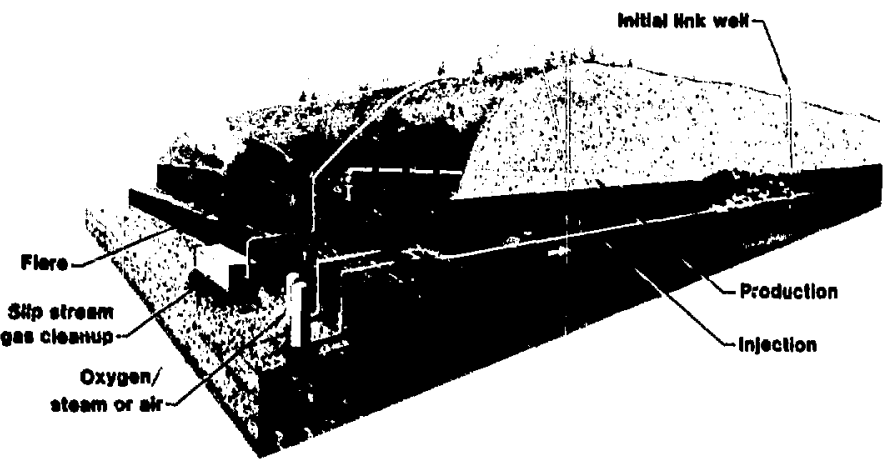

CRIP retractions, the intersection of the cavity with the production channel also moves back, ensuring a continuous gas connection with a low pressure drop.

Our second proposed experiment, a full-seam-thickness test run for 90 days, includes some gas-utilization experiments. We hope to adapt this test to provide a small commercial-scale system by drilling additional holes, cleaning up the field gas, and building a pipeline to the nearby power plant, where the gas could be used as a supplementary boiler fuel.

A preliminary cost estimate indicates that if applied to a coal mine with a high-wall geometry, the CRIP technique can produce raw, medium-quality gas at a very reasonable price of about $\$ 1.50$ per million Btu. Together with a potentially large increase in deep-coal recovery, the low production price makes the system very attractive as a source of supplementary boiler fuel for generating electric power at the mouth of the mine.

\section{Summary and Conclusions}

The five experiments of the largeblock coal-gasification series answered many of the questions they were designed to address. We emphasize that our conclusions apply to the particular coal seam in which the experiments were conducted; a different type of coal might behave differently.

Neither the composition of the product gas nor the cavity shape varied significantly with the ratio of injected steam-oxygen or with its flow rate over the range tested. (The slagging associated with the high-ash coal in the Big Dirty seam precludes operating at steam-oxygen ratios of less then $1: 1$,) The general shape of the air-burn cavity did not differ from those of the steam-oxygen burns.

The pressure that built up during the burns was almost certainly due to the formation of the large rubble zones in the burn cavities. Rubble builds up from the collapse of coal dried by the hot product gases, and the burn proceeds by oxidizing the rubble in the vicinity of the injection point. Burn cavities tend to be higher than they are wide, a natural consequence of their growth by shrinkage-induced collapse. So long as the cavity remains entirely in the coal, the rubble pile grows faster than it is consumed.

The product gases flow through the interstices of the rubble pile (and through temporary channels formed by the gas in the rubble pile) to the exit channel. If the velocity of the gas is high enough, some rubble can be carried through the well casing to the 
surface. Because the gas flows through a bed of coal rubble, its quality is consistently high and quite constant with time.

The CRIP experiment successfully demonstrated the technique of retracting the injection point and the feasibility of establishing a new bum zone. Because the first burn period was too short to consume the rubble pile and thus cause the heating value of the product gases to decline, the CRIP test did not produce any significant improvement in gas quality. We are confident that such an improvement would occur in a Ionger test. 4

Key Words: coal gasification; controlled retracting injection point (CRIP); large-block experiments; underground coal gasification (UCG).

\section{Notes and References}

1. Details of the Hoe Creek experiments were given in R. W. Hil!, C. B. Thorsness, R. J.
Cena, W. R. Aiman, and D. R. Stephens, "Results from the Third LLL. Underground Coal Gasification Experiment at Hoe Creek," in Proc. Sixth Underground Coal Conversion Symposium, Afton, Oklahoma (july 1980).

2. Plans for the large-block tests were described in R. W. Hill, C. B. Thorsness, and D. S. Thompson, Large Block Tests - Experimental Plati, Lawrence Livermore National Laboratory; Rept. UCID-19224 (1981)

3. The CRIP technique was described in R. W. Hill and M. J. Shannon, The Comprolled Re'trating lnjettion Pont (CRIP) Systim: A Mutifiret Strian Mrthod for In Silu Cual Gasifica(iii), Lawrence Livemiore National l.aboratory, Rept. UCRL-85852 (1981)

4. Labomtary studtes leading to the large-hlock tests were discussed in C. $B$. Thorsness and R. W. Hill, "Coal Block Gasification Experiments: Laboratory Rosults and Field Plans," in Proc. Seventh Underground Cosl Conversion Symposium, Fallen Leaf Lake, Califo:nia (September 1981).

5. Further details on the geology of the site may be found in L. C. Bartel and S. L. Love, Final Report - Sile Sriection and Charncterizafion for an Lunderground Conl Gnsification Test in Washinglem Statr. Project Defails, Sandia National Lahoratory. Albuquerque, New Mexico, Rept. 81-2051/11, Vol. II (1981). 

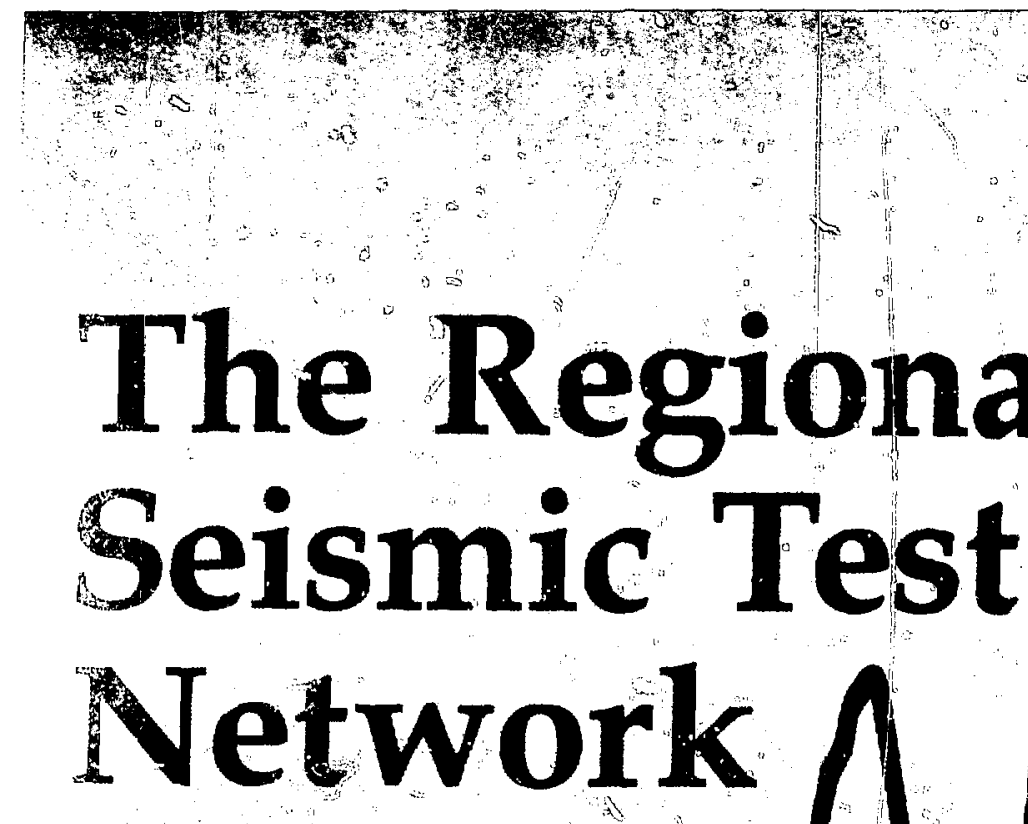

Future treaties limiting or banning nuclear tests will require accurate and reliable technical means of monitoring compliance. To this end, we are studying the performance of a regional seismic-detection network that sintulates anticipated conditions in the Soviet Union.

For further triformation contact

Steven R. Taylor (4T5) $123-0616$. 
During the pert two decedes, the . Unived Sutes and the Soviet Untion have sioned several trentes placing constrintints on the testing of nudear weapons. The Limited Test Dan Traty of 1963 prohibits atmoipheric nuciest tests. The unurified (but obverved) Thishold Tyet Ban Treaty (1974) and the Peaceful Nudear Explpaion Thenty (1976) limit weapons teits and peaceful applications, respectively, to $150 \mathrm{kt}$ for single explosions. The consumation of a future agresment lowering the current uilderground yield threshold or prohibiting the testing of nuclear weapons in any environment, such as the proposed tomprehensive Test Ban Treaty, would sequire, among other things, accurate and reliable technical means of monitoring compliance. ${ }^{1}$

The goal of LLNL's Test Ban Theaty Verification Research Program is to improve this nation's ability to monitor and verify compliance with present and

\section{future treaties liniting or
banning nuclear tests. La
the Department of}

National Laboratories (SNL) to develop the instrumentation for an in-country seismic monitoring system, to be known as National Seismic Stations (NSS), suitable for deployment in the Soviet Union. At the same time, DOE requested LLin: tion sites, defining the seismic performance of the system, and assessing the quality of the seismic data it would produce.

To provide operational experience with the NSS prototypes and to obtain data similar to those expected from NSS deploged in the Soviet Union, the DOE has instulled a Regional Seismic Test Network (RSTPi) in North America.' The RSTN has several galls, among them to provide engineering $e x$ perience in the sitting and operation of sophisticated seismic equipment under "rigorous climatic conditions and to evglunte the performance of a regional
fNetwork in a zeological er vironment similar to thit found ir much of the Soviet Union. In addition, because some earthiquakes and explosions look allke at low nagnitudes, zother goal of the RSTN is to determine the extent of low-level seismicity and to compare "It with the distribution of higher mag: nitude events since this will affect the number of seismic stations and the data-processing capabilities that are needed.

SNI. and the Nevada Operations Office of the DOE deployeal the RSTN at flve sites in North America. The stations, spaced about $2000 \mathrm{~lm}$ apart (Fig. 1), transmit high-quality broadband seismic data via satellite to several seismic reconding and aralysis centers, including one at LLNL.

The design and operation of an effective NSS system presents some chailenging verification problems. Chief among these is the discrimination of natural geismic events such as earthquakes from underground nucl aar explosions at low 
however, especially if the nearest detecting station is greater than two or three focal depths ( 30 to $50 \mathrm{~km}$ ) from the source and if the intervening geological and geophysical structures are unknown.

Theoretical and empirical studies of large events have shown that several

Fig. 1

Location of Reglonal Salumic Teal Notwork monitoring stations and the ansocisted raceiving stations In North Americe. The network conetefe of five selsmic stalions epeced about $2000 \mathrm{~km}$ apart. Wh are efudylng the reaponse of the system to earth. quakes in the selemic reglone of inter. est (Now Madrld, Mlasouri, the St. Lawrence Seaway, and the Yukon Torritory) and to underground explosione at the Novada $T_{j}$ at Site. fundamental differences between earth quakes and underground explosions act to produce distinctive seismographic records. An explosion, for example, radiates compressional or $\mathbf{P}$ waves that move away from the source, usually producing an initial upward and outward motion at the earth's surface (Fig. 2). An earthquake, ir contrast, occurs along a fault, and the initial motion of seismic waves can be either upward and outward from the source or

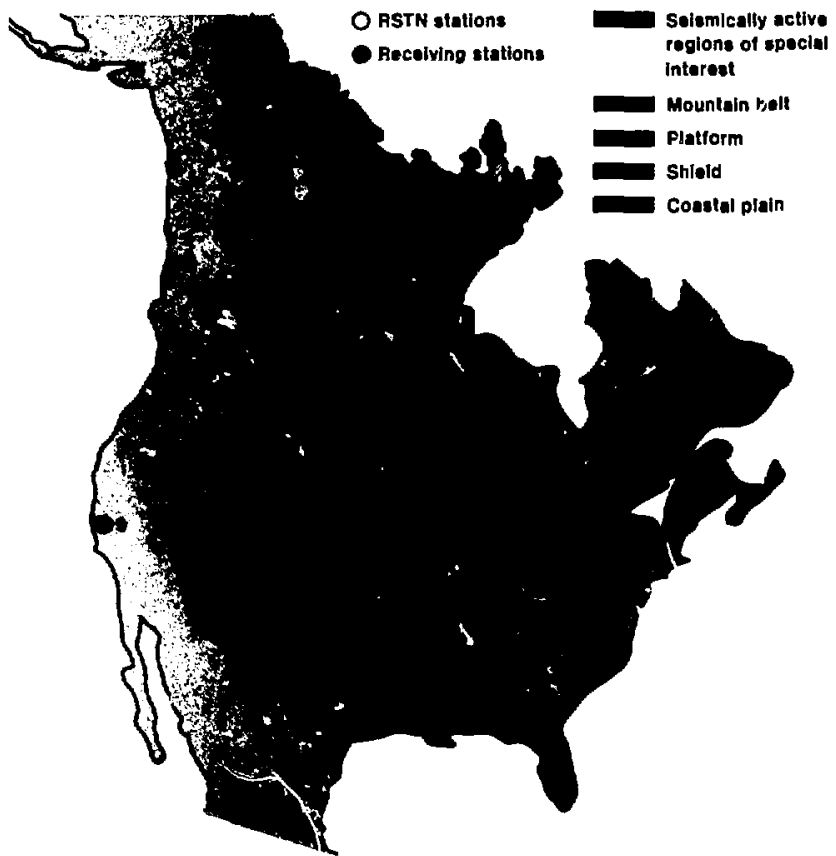

1. Yellowknite, N.W. Territory, Conada

2. Red Lake, Ontario, Cenada

3. Black Hills, South Dakot.

4. Adirondacks, Now York

5. Wahington, D.C. downward and inward toward the source, depending on the direction relative to the orientation of the faulit (see Fig. 2). The motion from an earthquake is produced by shearing forces that generate a significant amount of S-wave or shearing energv and subsequent surface-wave energy (sif box on p. 16). An explosion, in contrast, is a relative!y poor generator of shiar and surface waves.

Studies have also shown thit earthquake and explosion sources tilat radiate similar amounts of energy, ennit different source spectra (Fig. 3). Biecause of its small volume and its impulsive source-time behavior, an explesion produces an amplitude spectrum with a peak that is absent from the spectrum of an earthquake of similar si:te. This difference, together with the weak shear energy of an explosion, enables us to characterize a source by the ratio of the magnitude of its body' waves $m_{b}$

\section{Seismic Wave Propagation}

An event such as an tearthquake or an underground nuclear explosion generates seismic waves that propagate through the earth. At teleseismic distances (more than $2000 \mathrm{~km}$ ), the waves of interest are of two types: body waves, which travel through the earth, and surface waves, which propagate along the surface. There are two main kinds of body wave: the $P$ or compressional wave and the $S$ or shear wave. One type of surface wave, which appears on the vertical-component seismogram, is called a Rayleigh wave. We determine body-wave magnitude $m_{b}$ by measuring the amplitude of the $P$ wave at $1 \mathrm{~Hz}$, and surface-wave magnitude $\mathrm{M}_{\mathrm{s}}$ by measuring the amplitude of the Rayleigh wave at $0.05 \mathrm{~Hz}$. The $m_{b} / M_{5}$ discriminant, used to distinguish between explosions and natural earthquakes, is the ratio of these two magnitudes.
7. SCARS, Albuquerque, New Mexico

8. Neveda Test Site

9. LLNL 


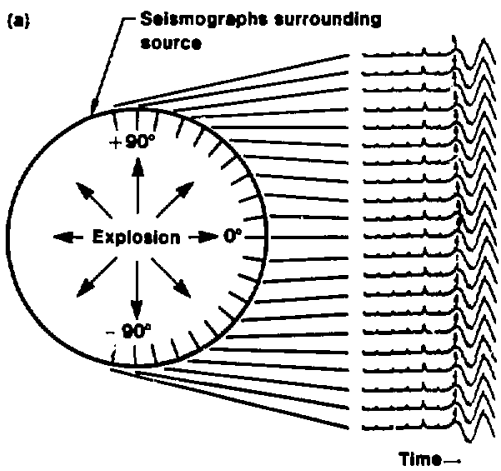

Fig. 2

Radiation of ablemtc P waves from an explosion (a) and from an earthquake (b). Because the explosion is a compresslonal source of energy, the $P$ waves produced are polarlzed in the redially outward direction. Thus, an initial upward and outward mollon will usually be observed on the surface of the eerth. In contrast, in earthquake generally occurs along a linear fuult that cen be represented as a force (b)

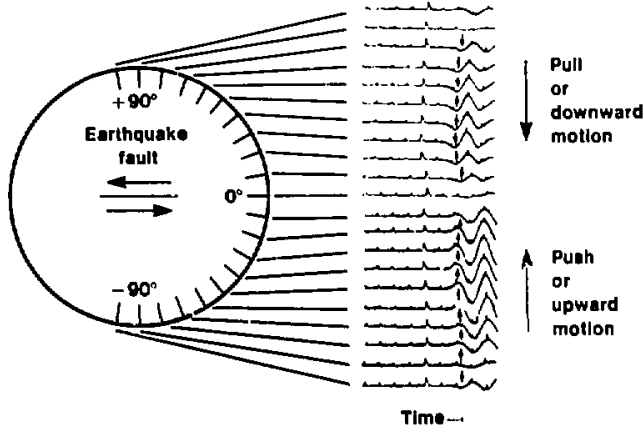

couple. Stallons located in 1 direction toward which a block moves will therefore observe an initial comprestional (upward and outward) mo. tlon. Stations located in a direction from which a block moves away will racord a dllatational (downwerd and inward) motion. The amplitude of the motion obnerved depends on the direatlon of the station in reiation to the orientation of the fault. (Floure adapted from F. Press and A. Siever, Eerth, W. H. Freeman ano Co., San Francieco, 1974.)
Because the national seismic monitoring stations will be located within the country they monitor, many of them will be at regional cistances (less than $2000 \mathrm{~km}$ ). Regionai seismic signals travel mainly in the upper mantle and crust of the earth (not shown to scale in the figure) rather than through the deep mantle. A receiver at regional distances can detect both body and surface waves propagated through the crust. Because of shearing that occurs along its fault plane, an earthquake generates a significant amount of S-wave and surface wave energy. In contrast, an explosion, which produces little shear energy, is a poor generator of surface waves. The $m_{b} / M_{5}$ ratio, thus, is lower for an earthquake than for an explosion of similar magnitude. Because of their different propagation path, regional signals include more high-frequency components than do teleseismic signals. As an explosion radiates higher seismic frequencies than an earthquake, we also can use the

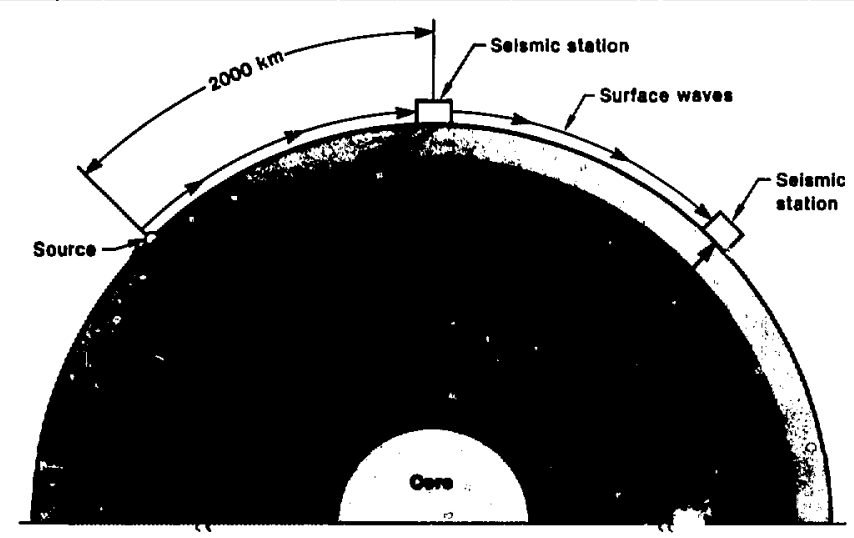

ratio of $P$-wave spectral amplitudes at different frequencies to discriminate the two source types. It must be noted, however, that many of these differences between earthquakes and explosions are not well established, particularly for $m_{b}$ values less than 3.5 . 
Fig. 3

Typical source epectra of in earthquake and an explosion. Becenuse of its emall volume and source-time behavior, en explosion generates an amplifude spectrum characterized by : peak that is abeent from that of an earthquake. Thus, for an earthquake and explosion with a simllar aurfacewave magnitude $\omega_{1}$ (meatured al $0.05 \mathrm{~Hz})$, the explosion will have a iarger inltial compresselonal wave $m_{b}$.

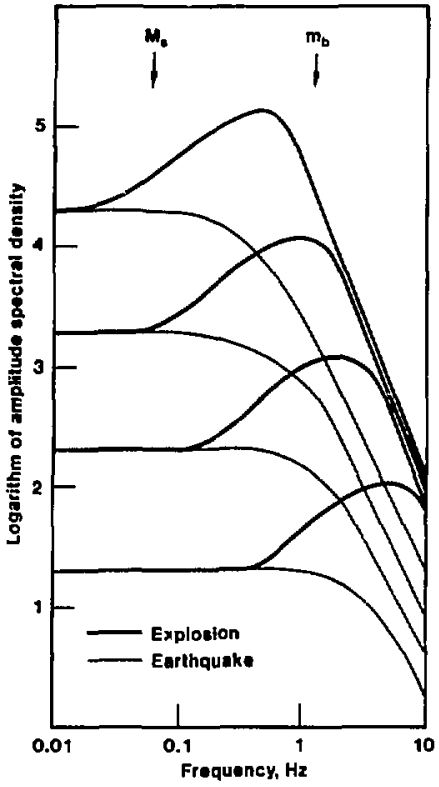

(those that travel within the earth's interior) to the magnitude of its surface waves $M_{s}$ (those that travel along the earth's surface), a quantity called the $m_{b} / M_{s}$ discriminant. An earthquake exhibits a lower $m_{h} / M_{s}$ ratio than does an explosion of similar size.

Finally, an explosion radiates higher seismic frequencies than an earthquake (see Fig. 3). This feature enables us to discriminate the two types of source by taking the ratio of their spectral amplitudes at different frequencies for a particular phase. These differences are illustrated in Fig. 4, which shows the energy-frequency-time diagram for an earthquake and for an underground nuclear explosion of similar size at the Nevada Test Site, recorded at one of LL.NL's broadband seismic stations in Nevada. The earthquake seismogram also shows larger surface waves than that of the explosion.

All of the above-described differences between earthquakes and explosions are fairly well established for body-wave magnitudes greater than 4.5. However, the differences become more
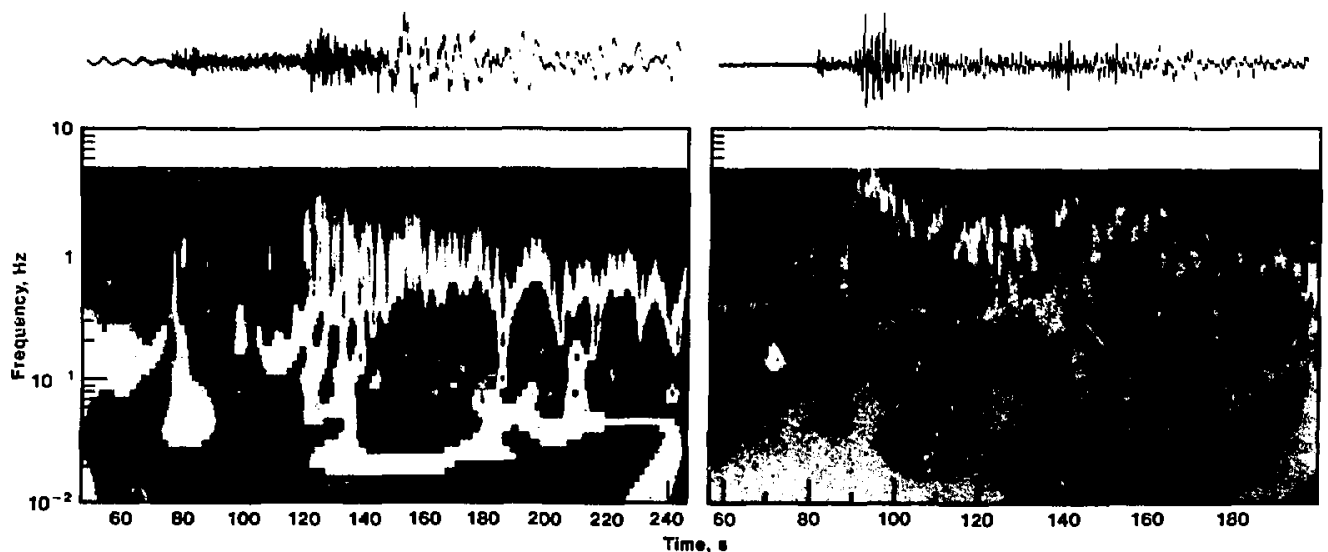

$$
\begin{array}{lll}
-4.5--4.0 \text { (green) } & -4.0--3.5 \text { (tt. blue) }-3.5--3.0 \text { (dk. blus) } \\
-3.0--2.4 \text { (pink) } & -2.4--1.9 \text { (belje) }-1.9--1.4 \text { (rad) }
\end{array}
$$$$
1.4-1.8 \text { (areen) }
$$$$
1.8-2.2 \text { (11. bluw) }
$$$$
2.6 \text { - } 3.0 \text { (pink) }
$$$$
3.0-3.4 \text { (belge) }
$$$$
2.2-2.6 \text { (dk. blue) }
$$

$$
3.8-4.2 \text { (yellow) }
$$

Fig. 4

Energy-frequency-time eslamogram for (a) an earthquake $\left(m_{0}=4.2\right)$ and (b) an explosion $\left(m_{b}=5.3\right.$ ) at the Novade Tect Site. Color con- toure show the normalized amplitude spectrum. The seismogram of the earthquake shows larger surfece waves than does that of the explosion for those relatively large events. 
subtle at smaller magnitudes and are often masked by poor signal-to-noise ratios. Thus, the RSTN will play an important role in determining how these features are manifested at low magnitudes (i.e., those appropriate to monitoring a Comprehensive Test Ban Treaty).

\section{Instrumentation of the RSTN}

The RSTN seismic system is designed to provide digital seismic data at both regional (less than $2000 \mathrm{~km}$ ) and teleseismic (more than $2000 \mathrm{~km}$ ) distances over a broad frequency range (from 0.02 to $10 \mathrm{~Hz}$ ). The instrumentation at each station consists of two three-component (vertical, rorth-south, east-west) borehole seismometers, a bi :,idband Geotech KS-36000, and a high-frequency Geotech S-750, the latter serving as a backup for the KS-36000. ${ }^{3}$ The seismometers are sealed in a tamper-proof package $6 \mathrm{~m}$ long that is emplaced in a borehole $19 \mathrm{~cm}$ in diameter at a depth of $100 \mathrm{~m}$ to reduce the effect of atmospheric noise (Fig. 5).

The data are transmitted to a satellite through a special unattended electronics package located on the surface near the borehole. The electronics package and a transmitting antenna $3 \mathrm{~m}$ in diameter are housed in a Fiberglas dome $5 \mathrm{~m}$ in diameter (see Fig. 5). The electronics and the antenna are powered by thermoelectric generators fueled from propane tanks. The satellite-transmitted data are received at the System Control and Receiving Station (SCAI:S) at the Sandia National Laboratory in Albuquerque, New Mexico, and at other data-processing facilities such as those at LLNL. The seismic stations are remotely controlled and calibrated from the SCARS; other data-processing facilities have a receive-only capability. The electronics system for the seismic stations and the SCARS system were designed and are operated by SNL.

The broadband output of the RSTN seismometers is divided into three separate frequency bands before being digitized: a shert-period (SP) band from 1 to $10 \mathrm{~Hz}$, a mid-period (MP) band from 0.02 to $1.3 \mathrm{~Hz}$, and a long-period (LP)
Fig. 5

Typical RSTN site. To roduce the effects of surface roise, the seismic detection instrumen is are emplaced in a borehole $19 \mathrm{~cm}$ in diameter and $100 \mathrm{~m}$ deep. The 6-m-long instrument package contains two ents of three-component syismometers, an analogue-to-digllal converter, shaping fillers and ampllfiers, and a data authenticator. The Fiberglas dome, $5 \mathrm{~m}$ in diameter, houses the surface electronice and the eatellite antenna.

Fig. 6

Frequency response of the three ASTN bands: long period $(0.02$ to $0.05 \mathrm{~Hz}$ ), mld period $(0.02$ to $1.3 \mathrm{~Hz}$ ), and short perlod $(1.0$ to $10.0 \mathrm{~Hz}$ ). The vertical axis represents selsmometer output in terms of ground velacity. The separation of bands minimlzes the possibility of saturation and loss of data thet could result trom a single broadband output.

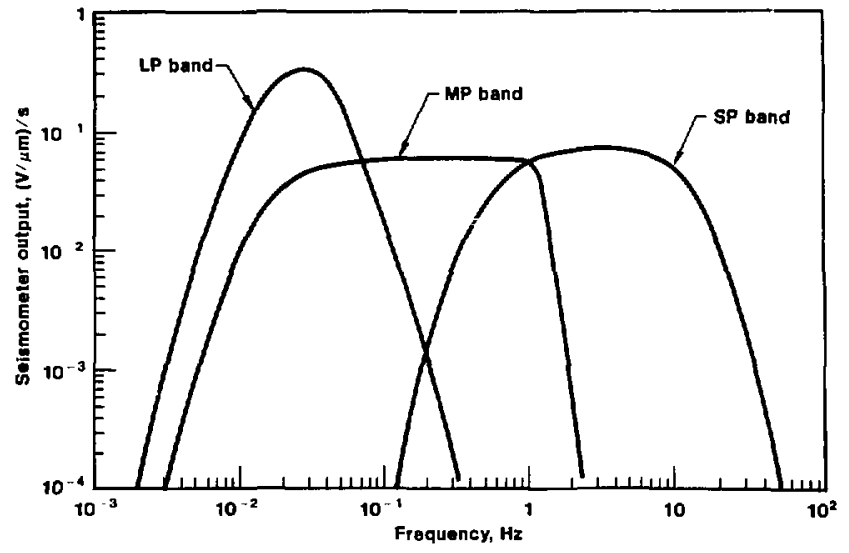


known, and if desired, the original broadband signal can be reconstructed at a data-processing center.

In addition to the seismometers, the downhole system contains a data authenticator and associated electronics equipment. The data authenticator ensures that the system is tamper proof. The electronics provides downhole analogue-to-digital conversion and automatic gain ranging, giving the system a dynamic range of approximately $126 \mathrm{~dB}$. This is remarkably high when compared with that of the World Wide Standarized Seismic Network, operated by the U.S. Geological Survey (USGS). This network (which records on photographic paper) and its digital version provide a dynamic range of only about 46 and $96 \mathrm{~dB}$, respectively, over a much narrower frequency band. The digital stations of the Seismic Research Observatory, also operated by the USGS, have a dynamic range identical to that of the RSTN but record only the SP and $L P$ bands.

\section{Discriminating earthquakes from}

explosions is probably the most complex task facing NSS seismologists, especially for small niagnitude events.

\section{Siting of RSTN Stations}

The locations of the five RSTN stations were recommended to the DOE by LLNL. The sites were selected to simulate as closely as possible the configuration proposed for the NSS and to approximate:

- The station separation that might be provided for under a Comprehensive Test Ban Treaty.

- The anticipated regional geophysical parameters for the NSS station sites.

- The anticipated geophysical properties between NSS stations.
In general, the geological and geophysical characteristics of much of the Soviet Union are believed to be similar to those found in eastern and central North America east of the Rocky Mountains. Both regions consist mainly of relatively old geological terranes and eroded mountain belts formed more than $\mathbf{2 5 0}$ million years ago. The geology of the southern Urals, for example, is very similar to that of the Appalachian Mountain belt, formed during the same geological era. Many geophysical characteristics of the two regions are also similar, including seismic velocities, crustal thickness, and attenuation, all of which are properties that govern the propagation of regional phases of seismic signals.

The eastern and central portions of North America are tectonically stable, being characterized by relatively low rates of seismicity. To simulate anticipated conditions in the Sovie' L'nion in regions of higher seismicity, some RSTN sites are located near more active seismic zones, such as those of New Madrid, Missouri, the St. Lawrence Seaway, and the Yukon Territory (see Fig. 1). Three of the RSTN sites (1, 2, and 6, Fig. ?) are located where a seismic station or array was already operating, thus providing historic information on site structure and noise characteristics. Because of the low seismicity rates associated with eastern North Arnerica, a minimum operating time of several years will be needed to adequately evaluate the network's capabilities.

Our sitemselection studies were divided into two phases. In the first, we used the foregoing considerations to locate the position of an RSTN site to within about $100 \mathrm{~km}$. In the second phase, we determined the exact station location. This entailed additional studjes involving the cooperation of seismologists, geologists, and engineers. Among the factors considered were seismic noise levels, observed signal-tonoise ratios, site accessibility, and geological structure in the region of the station. Low noise levels and high signal-to-noise ratios are important in determining a station's detection capability; a complex geological structure 
may complicate seismic waveforms and may make detailed analysis difficult once the station is installed.

Exact site selection proceeded in three steps. First, we selected a number of candidate sites for each region on the basis of a map survey. The candidate sites were located as far away as possible from natural noise sources such as lakes (because water waves couple with the earth to produce seismic excitation) and man-made sources such as highways and cities. Geological maps provided information on major regional structures that could disrupt seismic signals. We next made a reconnaissance trip to each candidate site to examine its cletailed geological charac: teristics and to take preliminary seismic noise measurements. Where possible, we obtained data from pre-existing seismic stations in the vicinity and used them to estimate the seismic characteristics of the region. Finally, seismic measurements were taken at each candidate site simultaneously over a period of two weeks. These measurements enabled us to compare the noise characteristics at each site. In addition, to study anticipated signal complexity, we analyzed seismograms from regional and teleseismic events. The final station site selected for each region was that characterized by the highest signal-tonoise ratio and by the least complicated seismic waveforms.

Once the sites were selected, the stations were installed by SNL. At each site, a borehole $15 \mathrm{~cm}$ in diameter was drilled to a depth of about $100 \mathrm{~m}$. A detailed description of each borehole was prepared, including geophysical measurements of sonic velocity and rock density, and core samples were taken. Finally, the seismometer package was emplaced and aligned in the boir hole, the above-ground electronics we $e$ installed, and transmission was begun.

\section{Operation of the RSTN}

The RSTN was designed to detect and locate seismic events, to discriminate earthquakes from explosions, and to infer geological structures in the vicinity of the network. The successful detection of treaty violations and the resolution of ambiguous events require the application of sophisticated data-processing techniques to suppress seismic noise (extraneous signals) and to enhance the signal characteristics of explosions. For example, signals must often be extracted from ambient earth noise or from other transients such as an interfering teleseismic event that occurs simultaneously with a regional event. The three recording bands of the RSTN enable us to perform much of this preliminary aralysis automatically in real time.

In the case of the signal from an event at regional distance mixed with an interfering teleseismic event, for example, the regional event is preferertially recorded by the short- and midperiod bands, while most of the energy of the teleseismic event appears in the mid- and long-period bands (Fig. 7). Signal-processing techniques can be used to further enhance signals for later analysis. For example, a polarization filter can be applied to a signal to separate linearly polarized signals, such as those from body waves, from elliptically polarized signals, such as those from Rayleigh waves (Fig. 8).

By automatically combining information on arrival time with azimuth estimates provided by the three recorded seismic components at each station, we obtain an initial estimate of the location of regional events. Accurate use of the travel-time data in this part of the analysis also requires some knowledge of earth structure. We are currently investigating the feasibility of placing a small (6-to 9-element) short-period array of sensors on the earth's surface around each NSS site. Such an array would improve the signal-to-noise ratio by summing signals and also would help to identify seismic waves, separate simultaneous events, and provide azimuth estimates superior to those from a single three-component station.

Discriminating earthquakes from explosions is probably the most complex task facing NSS seismologists, especially for small magnitude events. Some simple tasks, such as measuring the amplitude of various seismic phases, can be performed automatically by a 
computer to flag suspest events. However, the differences between certain earthquakes and explosions can sometimes be quite subtle, expecially (as noted) in a region whose geological and geophysical characteristics are not known in detail, and reliable discrimination will require careful analysis with sophisticated techniques. Among such techniques are the use of synthetic seismograms and multiple filtering.

Successful operation of any NSS system. will require additional studjes. Measurements of geophysical properties such as seismic velocities and attenuation characteristics are crucial to accurately locating seismic events and to identifying earthquake magnitudes or explosion yields. ${ }^{4}$
Fig. 7

A regional (a) and a teleselemic (b) event recorded on the vertical component for the three bands at the RSTN station in Sruth Dakote. The regional event is 1 om an NTS explosion $1275 \mathrm{~km}$ away ind the leleseismic event is from an earthquake in El Selvador $3841 \mathrm{~km}$ distant. Note that the long-perlod data for the teleselismic event is clipped at $10 \mathrm{~V}$; however lite information can etill be recovered from the mid-period channel. The regional event (the explosion) is characterized by higher frequencies and is recorded mainly on the mid- and ahortperiod bande. The teleselumle ovent (the earthquake), in contrast, shows the strongest signals on the long- and mid-period bands.

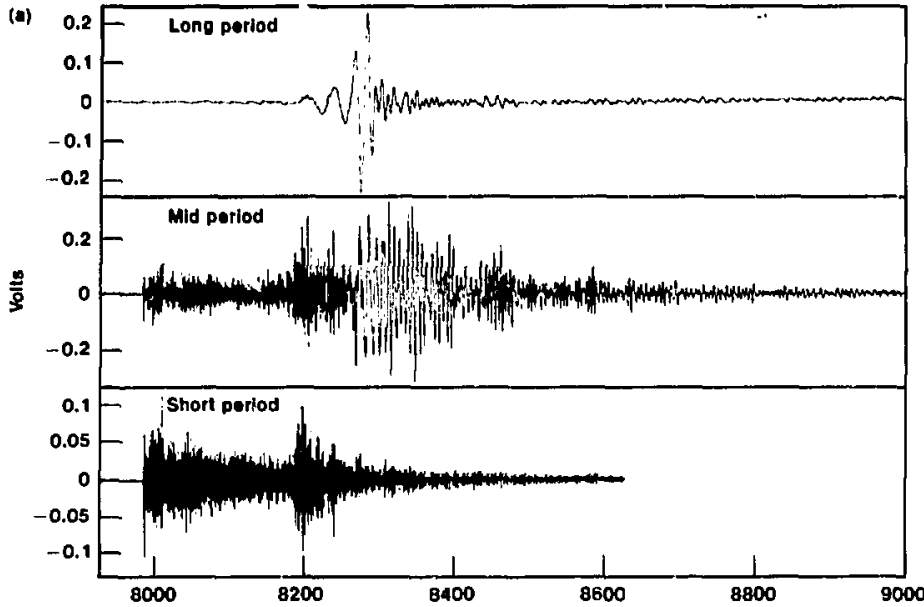

(b)

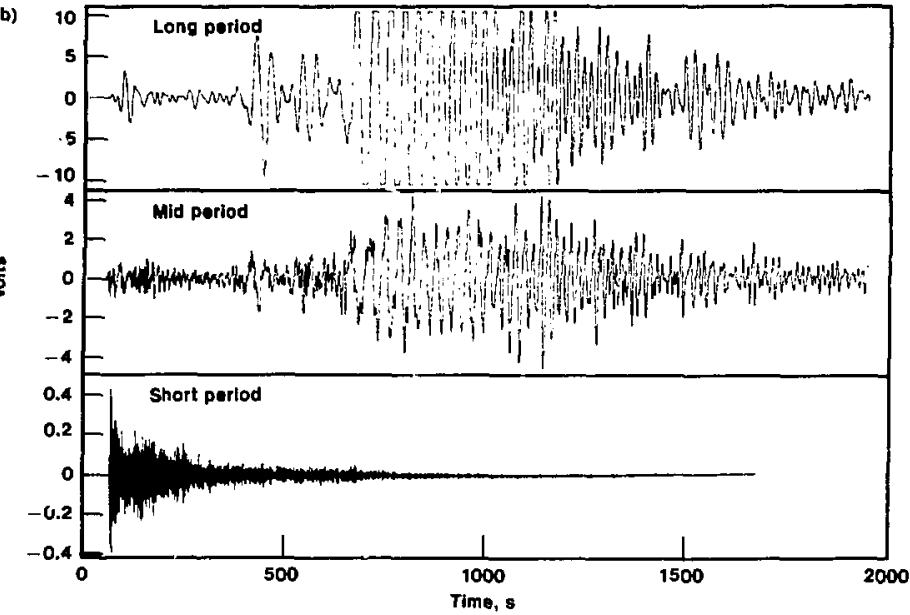




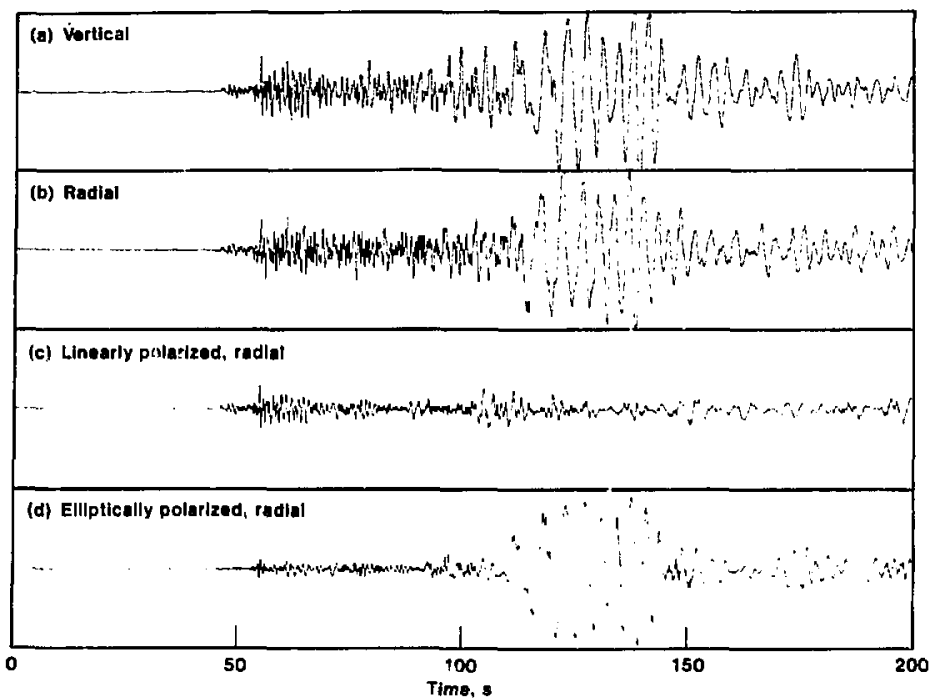

\section{Summary}

We are studying the performance and assessing the quality of data produced by the Regional Seismic Test Network installed in North America by the DOE. A similar but larger network might be deployed in the Soviet Union to monitor compliance with any suture Comprehensive Test Ban Treaty. Such seismic stations transmit high-quality, broadband seismic data via satellite to remote data-analysis acilities, including one at LLNL. The technical problems posed are complex, especially those involved in discriminating underground nuciear explosions f:om small magnitude natural seismic events and evasion attempts, and their solution will require the application of sophisticated dataprocesssing techniques. Studies lasting several years will be necessary to gain sufficient experience to ensure the accuracy and reliability of the system. $\mathbf{L}$
Key Words: Comprehensive Test Ban Treaty (CTBT); National Seismic Stations (NSS); Reyional Seismic Test Network (RSTN); Tes: Ban Treaty Verification Research Program.

\section{Notes and References}

1. For a discussion of the provisions of existing treaties on nuclear testing and some of the problems associated with monitoring underground nuclear tests, see the June 1981 Enor.y and Titholugy Retu'w (UCRI.-52000. 81-6), p. 19.

2. Deployment of the RSTN was the responsibility of the Nevada Operations Office of the DOE; participating organizations were LI.NL., Sandia National Laboratory, Alhuquerque, Holmes and Narver, and Edgerton, Gormeshausen, and Greer (EG\&G),

3. NSS instrumentation was described in $\Gamma$. A. Stokes, Thi Natimat Sristuic Stalim, Sandia Naiional Lahoratory, Albuquerque, New Mexico, Rept. SANDK1-2134 (1982).

4. Problems of attenuation in the earth's upper mantle were described in the March 1978 Energy and Terhnolugy Rerion' (UCRL-52000$78-3), p .10$.
Fig. 8

Ground motion produced by an explo. sion in the vertlcal (a) and radial (b) directions. (c) The radial signal has been processed by a iller that passes only energy that is linearly poiarized in the directlon radlat to the source, con. sisting mainly of oarly-arrlving body waves. (d) The radial signal has been proctused by a fllter that passes only waves whose parlicie motion is elliptlcal, at in late-arriving Rayleigh waves. 


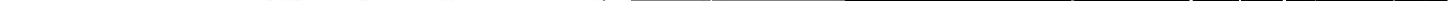




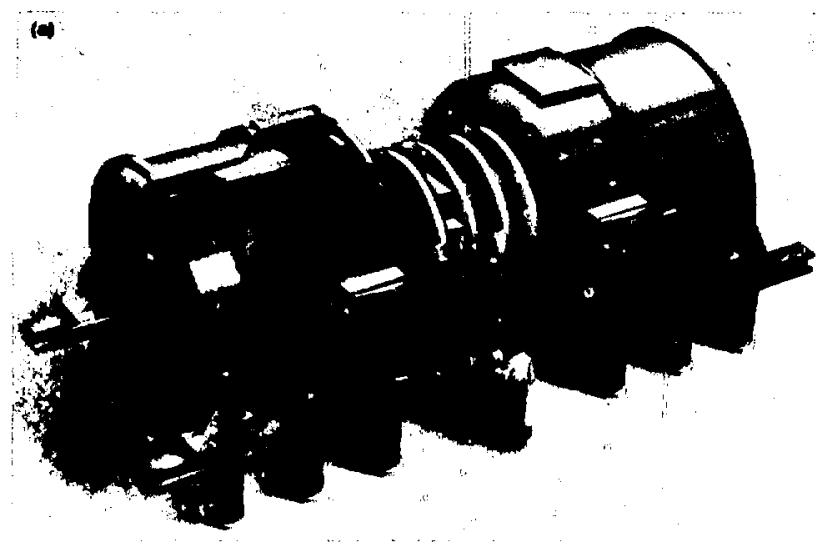

Fig. 1

Four representations of tandem mirror machine and the plane II contains. (a) Thu basic tandem mirror machine, including vacuum tonke, magnetic field coils, and noutral beem injectors. (b) All hardware has been removed excepl for the magnetlc colle; the plusma (orey) is thown. (c) The magnetic tleld colls have been removed to show better the simpe of the plasme cloud. The radial, asimuthal, and axlal directlone ere defined. (d) Axial proflles of the magnetic field strength (brown), alectrical potentlal (gold), and geodesic curvature ot a nonzero radial position (qreen). averaged over all of the particles to produce a reduced set of equations describing the macroscopic properties of the plasma and their coupling to the magnetic field.

Although this reduced set of equations is vastly less complicated than the full set of microscopic equations, their solution is still a significant computational problem, requiring the construction of large, sophisticated computer codes. One such code, developed at LLNL and called TEBASCO (Tandem Equillbrlum and BAllooning Stability CCde), has been used extensively to guide the design of the TMX-Upgrade and MFTF-B experiments at LLNL as well as mirror experiments at other U.S. laboratories.

By clarifying the role of the geodesic curvature in tandem mirror equilibria, MHD theory has had an important impact on experimental design. The geodesic curvature, described in Fig. 2, controls the component of plasma current flowing parallel to the magnetic field, which itself governs the magnitude and shape of distortions of surfaces of constant plasma pressure. Reducing the geodesic curvature by properly designing field coils reduces such distortions, thereby rendering the equilibrium more robust. An important corollary benefit is a reduction in radial transport (discussed in the next section). An illustration of this effect is given in Fig. 3, which shows the cross section perpendicular to the magnetic axis of constant-pressure surfaces at the center of a tandem mirror device. The solid curves indicate the equilibrium surfaces, while the dotted curves show where these surfaces would lie if the magnetic field were unaffected by the plasma. The distortion is fractionally quite small and therefore acceptable.

Having found a coil configuration that produces a robust plasma equilibrium, we next examine the stability of that equilibrium. The goal of MHD stability theory is to determine the maximum plasma pressure that can be confined by a given vacuum magnetic field.

In discussing MHD stability, it is helpful to introduce a new analogy. In place of the "bag of oranges," imagine 
the plasma and magnetic field as being rather like an old garden hose. If the water pressure is too high, a bulge or aneurysm may develop in the hose, as the water pressure pushes the flexible inner lining through a weak spot in the hose casing. The water corresponds to the plasma while the fibers in the casing correspond to the magnetic field.

Clearly, it is critical that the fibers be bound together strongly if the hose is to withstand much pressure. In this analogy, the nomnal curvature of the magnetic field produces the force that binds the magnetic field lines together. If the surface curves away from the plasma, the curvature is good in that it tends to bind magnetic field lines together. However, if the surface curves toward the plasma, the curvature is bad as it tends to pull the magnetic field lines apart.

In a tandem mirror machine, the curvature is good in the end cells at each end of the machine, while it is bad in the transition region between these cells and the central cell. Bad curvature can drive instabilities that allow the plasma to break out of the confinement region. The simplest and potentially most violent of these instabilities tries to push the magnetic field lines apart along the whole length of the tandem mirror, creating a plasma with a surface that is fluted like the shaft of a Doric column. These fluted perturbations are affected only by the average of the normal curvature alon; magnetic field lines. Tandem mirrors are designed in such a way that the averaged curvature is good; hence, these fluted perturbations are stable.

Returning to our garden hose analogy, one of these fluted pertuibations would correspond to a split running down the entire length of the hose. Such a catastrophe might be avoided by wrapping tape at intervals along the hose (the tape corresponds to the good curvature in the end cells). However, weak spots in the hose still remain in the gaps between these wrappings of tape.

Unstable bulges or ballooning modes may still exist, but they must be localized in the region of bad curvature. $A$

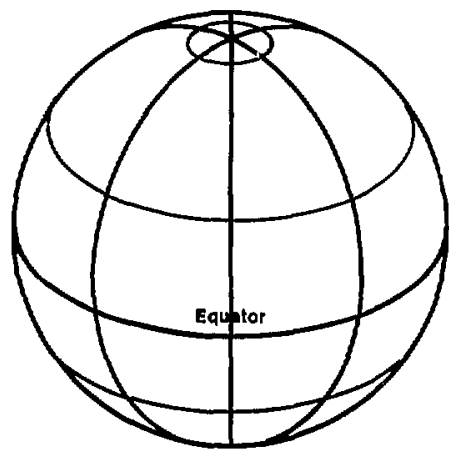

Fig. 2

Illustration of normal and geodesic curvature lor a curve on a aurface. The lines of longltude (brown) are known as greal circlos or geodesics; they have zero peodesic curvature (In the two-dimentional space of the vurface they are alralght) and nonzero normal curvalure (due to the curvature of the eurfece liself in three dimensiont). The sign of the normal curvature would be "bad" becausa there would likely be megnetohydro. dynamic (MHD) instabillty if the llnee of longltude were megnelle fleld llnos and the plasma were inalde the sphere. The lines of latitude (gold) are circles and have both nonzero geodesic and nonzero normal curvature. (Wo exclude the equatop hore becsuse th th a great clicte and has zero geodesic curvature.)

bulge in the plasma localized in the region of bad curvature bends the magnetic field lines as it expands, just as the corresponding aneurysm in our taped-up garden hose bends the fibers in the hose casing. The magnetic tension resists the bending of the magnetic field and, hence, tends to stabilize the ballooning modes. It is this magnetic tension that ultimately determines the maximum pressure at which a plasma can be confined.

Since the magnetic tension is proportional to the square of the field strength $\left(B^{2}\right)$, the balance between the plisma pressure (P) and the magnetic tension depends on the dimensionless parameter $\beta=2 \mathrm{P} / \mathrm{B}^{2}$. Large values of $\beta$ are desirable in the central cell of a tandem mirror device since the fusion energy output increases with increasing plasma pressure; in addition, the

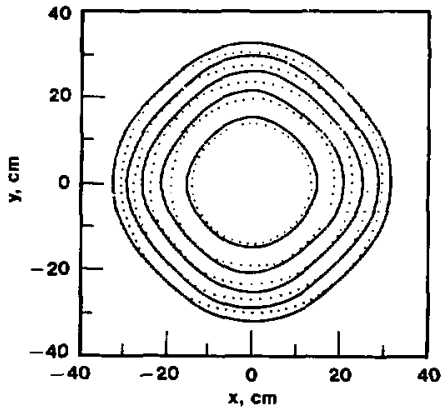

Fig. 3

Surfaces of constant plasma pressure in I tandem mirror. Shown are cross sections of the preseure surfaces at the center of a tandem mirror like TMX.Upgrade. The solld curves indlcate the pressure eurtaces in the equilibrium, while the dotted curves show where these surfaces would lie if the vacuum magnetic fletd were not distorted by the plasma. Although the preseure is quite high (ratlo of plasma to magnetic energy deneity $\approx 0.5$ ) the disfortions are smah, due to carefus design of the racuum fleld. 


\section{In designing a magnetic field to contain plasma, the foremost consideration is whether or not an equilibrium configuration of confined plasma and magnetic field exists; if there is no equilibrium, then all other issues become irrelevant.}

magnets needed to produce large values of $B^{2}$ (and hence reduce $\beta$ ) are expensive.

The maximum stable value of $\beta$ in the central ceil of a tandem mirror can be increased by putting a conducting surface near the plasma. We can understand this from our garden hose analogy hy noting that the surface prevents the fibers from being bent outward from the plasma. Hence, for an aneurysm to expand, these fibers must be pushed to the side. The fibers are stretched further than they would be in the absence of the surface, so that they give additional resistance to the expansion of the aneurysm.

The computation of the maximum $\beta$ in a given vacuum magnetic field is a significant numerical problem. Our TEBASCO code calculates these values
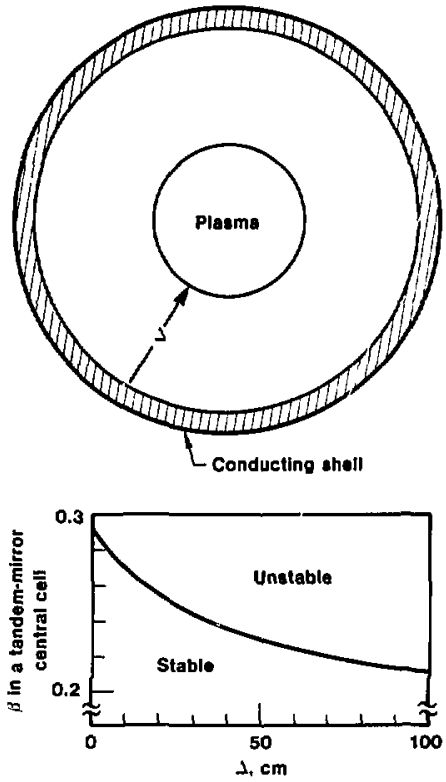

Fig. 4

Wall stabilization of preliminary MFTF-B coil design. The presence of a conducting shull around the plasma increases the maximum stable value of $\beta=2 \mathrm{P} / \mathrm{B}^{2}$ by $50 \%$ at the conducting shell lo moved from infinity to the surface of the planma. 
of $\beta$ in addition to solving for the MHD equilibrium. The ballooning-mode stability package in TEBASCO has been used extensively to er aluate various proposed coil configuritions during the design of the TMX-Upgrade and the MFTF-B experiment. An example of the information provided by TEBASCO to the design of MFTF-B is shown in Fig. 4, which presents the results of a study on the increase in the central cell $\beta$ that can be achieved by placing a conducting shell near the surface of the plasma. As the gap between this shell and the plasma is reduced, the maximum stable $\beta$ in the central cell increases by more than $50 \%$.

\section{Radial Transport}

A robust equilibrium with MHD stability at sufficiently high pressure must have workably small rates of particle and energy loss. Otherwise, the proposed tandem mirror device will require too large an expenditure for particle and energy sources. The losses are either axial (out the ends of the device) or radial (out the sides). Axial losses can be minimized fairly simply by choosing optimum axial profiles of magnetic field strength and potential.

Radial losses, however, are more difficult to control. An important cause of radial losses is the departure of tandem mirror devices from axisymmetry (i.e., symmetry about the long axis of the machine), which leads to nonzero geodesic curvature. In brief, the nonzero geodesic curvature causes charged particles to take small steps across the magnetic field in the radial direction. The net effect of numerous steps, some radially inward, the rest outward is radial diffusion (or transport) of the particles and the energy they carry.

The curvature of magnetic field lines leads to a slight, but important, change in the trajectories of charged particles, as shown in Fig. 5. If the field lines are straight and the field strength is independent of spatial position (a), a charged particle moves in a helix parallel to the field lines. The helix can be replaced by a straight line parallel to the field lines if we simultaneously replace the particle by a "guiding centex," a hypothetical particle-like entity bearing energy and an intrinsic magnetic moment. If, however, the field lines are curved (b), the guiding center does not move parallel to the lines, but slowly drifts across the magnetic field lines. The geodesic component of the fieldline curvature turns out to cause guiding centers to move from one surface of constant plasma pressure to another, which is approximately radial motion if we regard the plasma as be.ng approximately cylindrical in shape. The normal curvature causes azinuthal guidingcenter motion, as does a radial gradient of electrical potential or magnetic field strength.

(a)

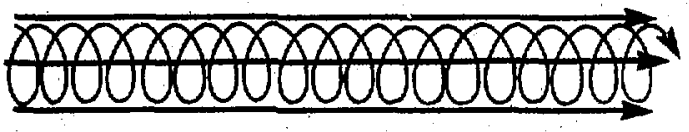

(b)

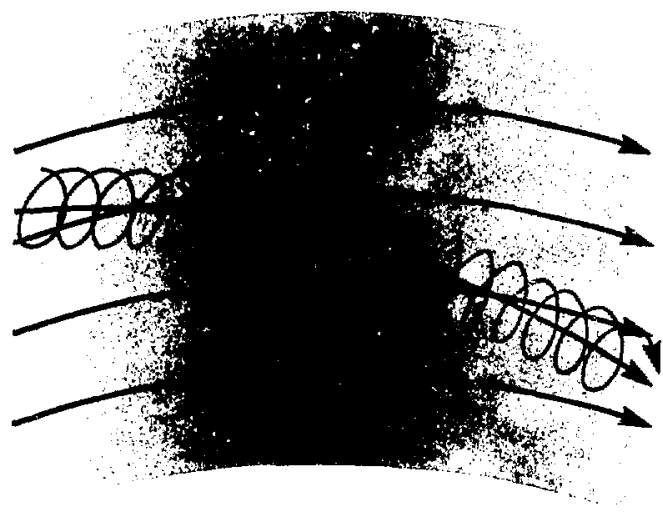

Fig. 5

Trajectories of a charged particle (cold) and its guiding center (brown) in magnetic flolds with (a) straight and (b) curved fleld IInes.

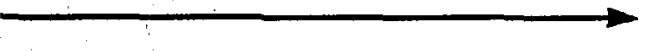


Next, jmagine a guiding center moving within the central cell between the regions of high potential and field strength in the end cells. Tandem mirror devices are built with a symmetry such that a guiding center with no azimuthal motion experiences opposite geodesic curvature at the two ends of the central cell and therefore no net radial displacement. Typically, however, the azimuthal drift rate is large enough that an ion guiding center can be displaced azimuthally by $90 \mathrm{deg}$ while: moving from one end of the central cell to the other and experience the same geodesic curvature at the two ends and thus a nonzero radial displacement or step. During the time it takes for a particle $o$ bounce many times between the ends of the central cell, the guiding center will pierce a plane crossing the plasma at the center of the device at points that may lie on the bananashaped curves shown in Fig. 6.

The problem of radial transport occurs when guiding centers fail to trace out banana-shaped curves. This failure can be caused by Coulomb collisions, which force a guiding center to exchange one banana curve for a second at a radial position different from that of the first. A guiding center also fails to trace out a banana-shaped curve if curves at different radial positions become so wide that they touch. This occurs if a guiding center has rapid radial and azimuthal motion; as a result, the guiding center becomes "confused" about which banana curve it is supposed to trace out. Both of these mechanisms for radial transport are based on

Fig. 6

Representation of the trajectories of five ion guiding centers in a tandem mirror central ceitl. Each time a gulding center passes tyrough It . ntral plane of the mirror suechine a point is placed on the plot to record the spr. tial position in thal plane. Two of the guiding centers trace out bananeshaped curves, one at a radius of $10 \mathrm{~cm}$ and the other at $40 \mathrm{~cm}$. guiding center motion and thus depend significantly on the geodesic curvature. Reduction of geodesic curvature through careful design of the magnetic field coils reduces radial transport.

Another promising technique for reducing radial transport is to add an axisymmetric throttle to the standard tandem mirror configuration (see Fig. 7). The throttle is a region of high magnetic field strength that allows only a small fraction of particles in the central cell to enter the nonaxisymmetric end cells where the geodesic curvature is large. The throttle can reduce radial transport by as much as a factor of ten if the throttle can be added without changing the geodesic curvature.

\section{Fokker-Planck Calculations}

A plasma can be described in detail in terms of the distribution functions of ions and electrons. At any point in space, these functions describe the velocity distributions of the particles. The numerical value of a velocity distribution function at a given vectorial velocity is proportional to the probability that a particle has a velocity near the given velocity.

Numerous processes cause ion distribution functions to change over time. A Coulomb collision of one ion with another ion or with an electron changes the velocity vector of the ion in magnitude, direction, or both. Many such velocity changes may allow the velocity vector of the ion to be sufficiently aligned with the magnetic field so that the magnetic mirrors (i.e., the regions os high field strength) fail to reflect the ion, allowing it to escape to the end of the mirror device. An ion can also be lost if it collides with a neutral atom and exchanges an electron with it. Then the neutralized ion can move in a straight line across the magnetic field to the side of the device. An ion is injected into a mirror device in the form of a neutral atom that, upon collision with a charged particle already in the plasma, loses an electron and thereby appears suddenly as a new plasma ion. We inject low-energy atoms by letting room-temperature gas into the vacuum chamber containing the plasma, and we 
inject high-energy atoms that we produce as a multi-kiloelectron-volt beam of neutral particles.

These source and loss processes are included in a partial differential equation known as the Fokker-Planck equation. We numerically advance this equation in time until the ion distribution function stops changing; then we plot the results.

A contour plot of the velocity distribution for confined ions at the center of the TMX-Upgrade end cells is shown in Fig. 8. Contour lines connect points in velocity space that have the same distribution-function value. In Fig. 8 , there are two maxima representing two components of the ion distribution: near zero velocity, there is a peak for warm (i.e., low-energy) ions (a), and at approximately equal perpendicular and parallel velocities of $8 \times 10^{7} \mathrm{~cm} / \mathrm{s}$, there is a peak for hot (high-energy). sloshing ions (b). The empty region in the lower right of this figure is the loss cone. Ions in this region are not confined by the magnetic field but are lost out the ends of the device as soon as they enter this region. The detailed form of the distribution function is important in determining the microstability properties of the system, as described in the next section.

The numerically calculated distribution function can be directly compared with experimental measurements of the distribution function as determined from the flux of charge-exchange neutral particles emitted by the plasma. $A$ charge-exchange neutral particle leaves the plasma with the same velocity vector it had as a confined ion at the instant that the charge-exchange event occurred. The velocity vector and spatial origin of the charge-exchange neutrals are measured by a device called a charge-exchange neutral analyzer. The flux of charge-exchange neutrals into the analyzer within some small velocity interval is a direct measure of the velocity distribution of the ions in the plasma for the same velocity interval. A favorable comparison between the numerically and experimentally determined ion distribution function serves to verify the correctness

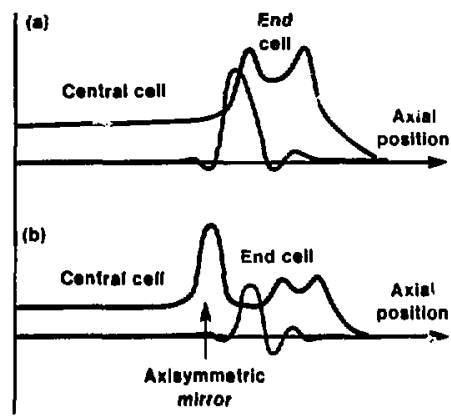

of the theoretical model used for the Fokker-Planck calculations, and gives some confidence in predicting the distribution functions for plasmas with parameters different from those in the experiment.

It might seem that the best way to maximize the ion cunfinement time against collisional diffusion would be to inject ions with velocity vectors strictly perpendicular to the magnetic field
Fig. 7

Magnetlc figld (brown) and geodesic curvature (gold) protlles for (a) slandard landem mirror and (b) tandem mirror with high-field axisymmotric mirror added.

\section{Fig. 8}

The ion velocliy distribution for a TMx-Upgrade end plug. Contours and shading how the peaking of the disirlbution in the yicinity of the sources at (a) low energy (warm-gas ionization) and at (b) high energy (neulral-beam injection with the perpendicular and parallel velocity components equal). lons diffuse via Coulomb collisions from these sources toward the empty lose-cone region where they escape along field lines to the end of the device.

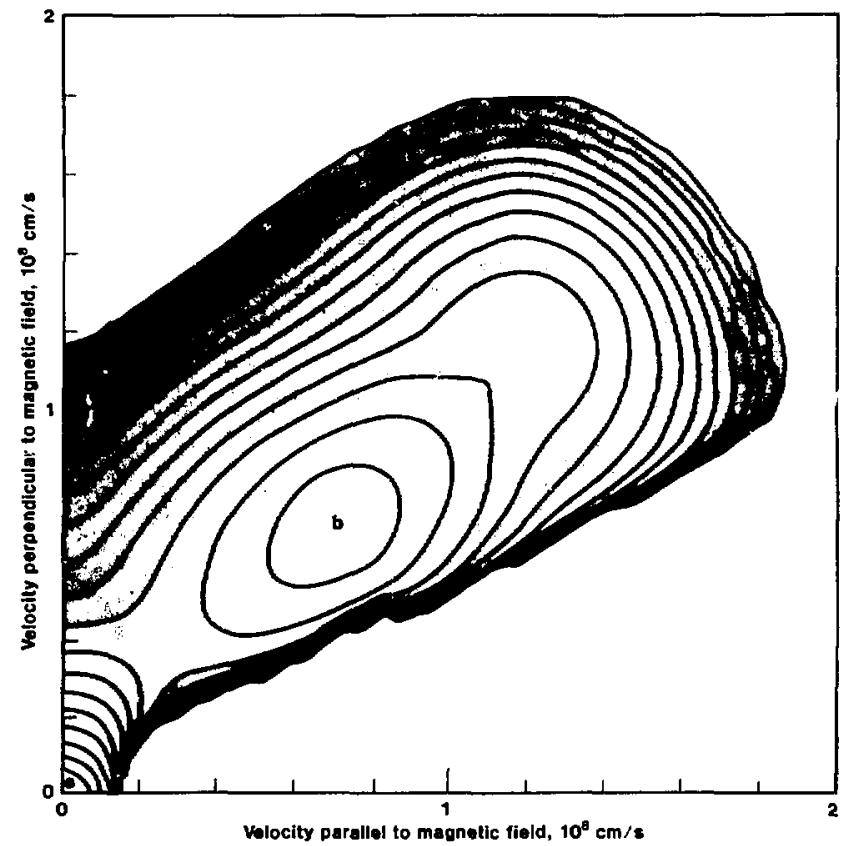


Fig. 9

Enlargement by an electrical potenlial dip of the veloelty-epace replon in which lons are conflned in a magnetic mirror machine. The solld curve shows the edge of the continement region in the sbsence of a dip in the axial potential profile. Nole that ione with low kinetic energy are unconfined. The danted curve showe the enlargement of the continement reglon when a potential dip is present. in this cese, low-energy ione are confined.

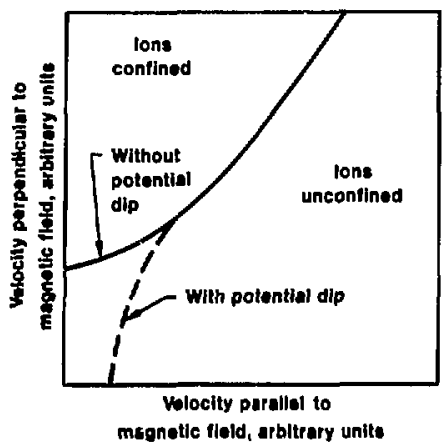

lines at the point of minimum magnetic field strength. However, this strategy yields microinstabilities that increase ion loss to the end of the device. Injecting ions with velocity vectors closer to the direction of the magnetic field means that Coulomb collisions can more readily cause end loss, but this results in a longer confinement time because microinstabilities are absent. The trade-off between collisional diffusion time and microstability is the key to choosing an injection strategy for magnetic mirrors. Technological constraints such as beam quality and accessibility of injection angles limit the freedom to choose a totally optimum system configuration.

\section{Microstability}

Quantitative information about patticle distributions in velocity space, as

\section{Fig. 10}

Characteriatice of en ion distribution stable to loss-cone microinstabilities. The curve showe the ratio of warm-ion denelty to hot-ion denelty required for stability as a function of the ratio of mean warm-ion eneray to mean hot-jon energy. provided by Fokker-Planck calculations, is important for studies of microinstabilities. A microinstability in a plasma is a growing wave of the type described by the Maxwell equations with the charge and current densities arising from the charged particles of which the plasma consists. These equations describe a temporally varying electromagnetic field that changes the velocities of the particles. A growing wave (i.e., an instability) occurs if the velocity changes result in charge and current densities that tend to increase the electromagnetic field that caused the velocity changes.

If a growing wave reaches large amplitude, the velocity changes it causes may lead to unacceptable rates of particle loss from the plasma-confinement device. To avoid these losses, we seek stable particle distributions (i.e., those for which waves do not grow) as well as methods to produce these distributions by appropriate fueling and heating techniques. The need for stable particle distributions leads to constraints on the profiles of magnetic field intensity and electrical potential along the axis of a tandem mirror plasma. These constraints, in turr, lead to limits on the achievable particle-confinement time. Below we give two examples of the constraints imposed by microinstabilities on particle distributions; both examples concern instabilities sensitive to the ion distribution.

Loss-cone instabilities are sensitive to the distribution of ions with kinetic energy below the mean kinetic energy. The low-energy ions are, in turn, sensitive to the axial profile of electrical potential. If a potential dip appears where the magnetic field intensity has a local minimum, an enlarged region of velocity space is used to describe the ions that are confined within the tandem mirror machine (Fig. 9). This en!arged confinement region at low energies allows us to build up a large ion distribution there that suppresses loss-cone instabilities. To determine how large the low-energy part of the ion distribution must be to ensure that the total distribution is stable, we plot the ratio of the density of warm (low-energy) ions to 
the density of hot (high-energy) ions as a function of the ratio of the mean kinetic energies of the warm and hot ions (Fig. 10).

Another microinstability, called the Alfvén ion-cyclotron instability, is sensitive to a different feature of the ion distribution-the distribution of velocity pitch angles. This distribution gives the probability that the angle betweer: the magnetic field direction and the velocity vector of an ion has a specified value. An important feature of the pitch-angle distribution is the angle at which the distribution has its peak value, To avoid Alfvén ion-cyclotron instability, we cannot let the density of the sloshing ions exceed a certain limit. This limit is higher if the ion distribution peaks at a pitch angle for which ions are traveling closer to the direction parallel to the magnetic field direction, as shown in Fig. 11.

By determining accurately the causes and results of microinstabilities like those discussed here, we can design and operate tandem mirror machines that reliably demonstrate the advantages of these plasma-confinement devices.

\section{Conclusions}

To develop the cheap, safe, and reliable tandem mirror reactors that will be accepted by electric utilities as useful power sources, we must extend our knowledge of the basic physical processes that are important in these devices. Here, we have discussed four areas of theoretical plasma physics that affect the design of tandem mirror devices. From calculations of magnetohydrodynamic equilibrium and radial

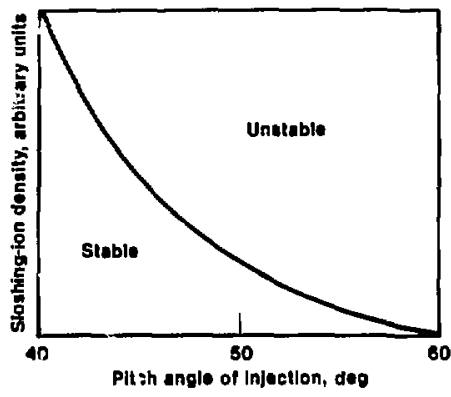

transport, we learn how to design a magnetic coil set in which a plasma can be produced. From magnetohydrodynamic stability theory, we determine the maximum pressure at which we can conine the plasma. From FokkerPlanck calculations, we gain detailed knowledge of the particle distributions in position and velocity space that result from various particle and energy injection strategies. Using microstability theory, we identify those distributions that are less susceptible to the growth of large-amplitude waves that would degrade the particle confinement times as determined by radial-transport and Fokker-Planck calculations. 6

Key Words: Fokker-Planck calculations, magnetic fusion energy (MFE), magnetohydrodynamic stability, microstability, MFTF-B, tandem mirzor devices, radial transport, TMX-Upgtade.

\section{Notes and References}

1. For a discussion of computer modeling of magnetic mitror experiments, see the December 1980 issue of Energy and Technolugy Revie'u (UCRL-52000-80-12). p. 15.
Fig. 11

Characterintics of an ion diatribution stable to the Alfien ion-cyclotron microin stability. The curve showe the maximurn deneity for atability as a function of the pitch ongle at which the distrlbution has ite peak value. We produce distributione with smaller pitch anglos by injecting neutral atom beame more nearly parallel to the megnetic rield. 


\section{Past Titles}

Articles published in recent issues of the Energy and Technology Review are grouped below mainly according to their chief sponsors, the Assistant Secretaries of the U.S. Department of Energy. Research ?unded by other Federal agencies is listed under Work for Others.

\section{ENERGY RESEARCH}

Successful MI:Tl:-B Technology Demanstration (Brief-May 1982)

\section{DEFENSE PROGRAMS}

Inertial Fusion

l.aker lusion with Green and Blue I.ight (August 1982)

Measuring Microsphere Targets for Fuston Experiments (June 1982)

\section{Military Application}

A Universal bensor for Potentiometric Titrations (Brisf-August 1982)

Electrosynthesis of $\mathrm{N}_{2} \mathrm{O}_{4}$ : the Key to Inexpensive $\mathrm{HMX}$ (August 1982)

The Compuron: How Round is Round? (August 1982)

New Cablo Emplacement Device Tested (Brief-June 1982)

The Raman Spectroscopy Microprobe (June 1982)

\section{LABORATORY HISTORY}

Energy and Resource Programs (October 1982)

Inertial Confinement Fusion (October 1982)

The Tandem Mirror MFE Program (Oclober 1982)

Chemistry and Materials Science in Retrospect (September 1982)

Computing at LLNL (September 1982)

Project Plowshare: A Brief History (September 1982)

The LLNL-Nevada Organization (September 1982)

Thirty Yoars Ago: Controlled Thermonuclear Reactions (June 1982)

\section{LABORATORY REVIEWS}

Energy and the Environment (July 1982)

LLNI. 1982: Technical Horizons (|uly 1982)

National Defense (July 1982)

Supporting Technologies (July 1982)

The State of the Laboratory (July 1982)

U.S. Oil Supply Reflects World Events (Brief-May 1982)

\section{NUCLEAR ENERGY}

Successful Demonstration of the AVLIS Process (Brief-August 1982)

\section{WORK FOR OTHERS}

\section{Department of Defense}

Improving Tank Track Pads (May 1982)

\section{Environmental Protection Agency}

Atmospheri Ozone: Zeroing In (May 1982)

\section{Nuclear Regulatory Commission}

Nuclear Waste Storage: Evaluating the Uncertainties (May 1982) 


\section{Disclaimer}

The document was prepsred as an accoun of werk sponsired by an agency of the United Statom Government. Nevither the Uniled States Gevern. ment nor the University of Callformia nor any of their employeess, makes any watranty, express or implied, or assumes any legal lisbility or respone shibity of any information, apparatus, proxtuct. or precess disclosed, or represents that its use would not infringe privately oritued rights, Reforence herein to ary specilic commencial products, pro. cess, or service hy trade name, trademark, manufacturer, or otherwise, does not mexessarily consli. tute or imply its bndorsenent, reconnmendation, or foloring by the United States Government or the University of Californis. The viesss and opinions of authors expressed herein do not necessarily stale or reflect those of the United Stales Governmiont thereol, and shall not bes used for advertising or product endorsement purposes.

Printed in the United States of America Availstile from

National Technical Information Service U.S Department of Conmerce

5285 Porl Royal Roat Sipringficld. Virginis 2216i

Price: Printed Copy \$4.50, Microfiche $\$ 3.00$ 